NBER WORKING PAPER SERIES

\title{
WEALTH AND INSURANCE CHOICES: EVIDENCE FROM US HOUSEHOLDS
}

\author{
Michael J. Gropper \\ Camelia M. Kuhnen \\ Working Paper 29069 \\ http://www.nber.org/papers/w29069 \\ NATIONAL BUREAU OF ECONOMIC RESEARCH \\ 1050 Massachusetts Avenue \\ Cambridge, MA 02138 \\ July 2021
}

Support for this work has been provided by the Kenan-Flagler Business School at the University of North Carolina at Chapel Hill. The views expressed herein are those of the authors and do not necessarily reflect the views of the National Bureau of Economic Research.

NBER working papers are circulated for discussion and comment purposes. They have not been peerreviewed or been subject to the review by the NBER Board of Directors that accompanies official NBER publications.

(C) 2021 by Michael J. Gropper and Camelia M. Kuhnen. All rights reserved. Short sections of text, not to exceed two paragraphs, may be quoted without explicit permission provided that full credit, including $\odot$ notice, is given to the source. 
Wealth and Insurance Choices: Evidence from US Households

Michael J. Gropper and Camelia M. Kuhnen

NBER Working Paper No. 29069

July 2021

JEL No. D14,G22,G51,G52

\begin{abstract}
$\underline{\text { ABSTRACT }}$
Theoretically, wealthier people should buy less insurance, and should self-insure through saving instead, as insurance entails monitoring costs. Here, we use administrative data for 63,000 individuals and, contrary to theory, find that the wealthier have better life and property insurance coverage. Wealth-related differences in background risk, legal risk, liquidity constraints, financial literacy, and pricing explain only a small fraction of the positive wealth-insurance correlation. This puzzling correlation persists in individual fixed-effects models estimated using 2,500,000 person-month observations. The fact that the less wealthy have less coverage, though intuitively they benefit more from insurance, might increase financial health disparities among households.
\end{abstract}

Michael J. Gropper

University of North Carolina

Michael_Gropper@kenan-flagler.unc.edu

Camelia M. Kuhnen

University of North Carolina

Kenan-Flagler Business School

300 Kenan Center Drive, MC \#4407

Chapel Hill, NC 27599

and NBER

camelia_kuhnen@kenan-flagler.unc.edu 


\section{Introduction}

Insurance products are ubiquitous. One in two US households have life insurance coverage, and the vast majority of households have property-related insurance coverage, such as homeowners or automobile insurance. ${ }^{1}$ Insurance is an important part of households' financial portfolios, yet we do not have much empirical evidence as to how people make these insurance-related decisions. There exists a substantial body of theoretical work on this topic, including the classical models of Mossin (1968) and Lewis (1989), or the more recent models in Gollier (2003) and Koijen, Van Nieuwerburgh, and Yogo (2016). These theories posit that one of the key factors driving insurance purchases is wealth. Specifically, the prediction is that wealthier individuals will choose to purchase less insurance, as insurance products come with a load, that is, monitoring and other fixed costs that make them costlier than self-insurance through saving.

Empirically, there is scant evidence on what factors drive insurance purchases, and most of this evidence is survey-based. In this paper, we examine administrative records of 63,000 people during 2015-2019, in a dataset of 2,500,000 person-month observations, to investigate whether actual insurance choices match the theoretical predictions. We document that the main prediction of standard models, namely, that wealth and insurance coverage are negatively correlated, is not met in the data. Instead, we observe a very strong positive relationship between a person's wealth and the extent of coverage secured through life insurance and homeowners and other property-related insurance, controlling for the value of the insured asset. For example, we estimate that a $\$ 1$ increase in financial wealth leads to an increase of 68 cents in a person's term life insurance coverage limit, and to an increase of $\$ 2.25$ in the coverage limit of their homeowners insurance policy. ${ }^{2}$

\footnotetext{
${ }^{1}$ Estimates of insurance coverage across the US population can be found in the LIMRA Insurance Barometer Survey or the Insurance Information Institute (III) Consumer Insurance Survey. For example, according to the III, $95 \%$ of homeowners have homeowners insurance. According to LIMRA, about half of the people who have life insurance policies purchase them individually, and the rest are covered by group life insurance, typically provided by employers.

${ }^{2}$ Our analysis of life insurance demand is restricted to term life insurance (as opposed to so-called "whole" life insurance). Term life insurance is a pure insurance contract which pays out a pre-specified amount (i.e.,
} 
We then seek to understand why the data do not match the standard theoretical predictions, to assess which features ought to be included in future models of household insurance choices to account for the seemingly puzzling positive relationship between wealth and insurance coverage. We first show that risk tolerance is higher for wealthier households, based on their allocation to risky versus riskless financial assets, and thus the assumption of diminishing risk aversion used in standard theories of insurance purchase is verified in the data. Hence the positive wealth-coverage correlation is not driven by the existence of risk preferences different from what standard theory assumes. We also examine insurance premiums paid per dollar of coverage to assess whether the wealthier households get better prices for insurance products. We find that if anything, wealthier households pay more in premiums per dollar of insurance coverage, potentially due to having more states of the world to which the coverage applies.

We document that wealthier households are exposed to higher consumption, income, and financial wealth volatility, suggesting that higher insurance coverage by these individuals is in part a response to facing a different distribution of economic shocks, or background risk, relative to their less wealthy counterparts. We also investigate whether wealthier households get higher insurance coverage due to increased litigation risk. We find that the positive relationship between wealth and property insurance coverage increases in states where expected payouts from civil lawsuits are higher, a finding akin to the result in Mahoney (2015) that weaker bankruptcy protection increases the demand for health insurance. We document that liquidity constraints (e.g., Baker and Yannelis (2017), Parker (2017)), financial literacy (e.g., Brown, Cookson, and Heimer (2019), Haliassos, Jansson, and Karabulut (2020)), or employer-provided benefits that may differ by wealth levels can also explain some of the positive wealth-insurance coverage pattern. That being said, controlling for these other mechanisms, we continue to observe that cross-sectionally, wealthier people are better insured. We

the coverage limit) in the event that the insured dies during the duration (i.e., "term") of the contract, which is also specified ex-ante. Unlike whole life insurance, term life insurance is not treated in a tax-preferred manner (Brown (2001)). Thus, the increasing demand for life insurance among the wealthy in our sample is not driven by tax considerations. 
then conduct within-person analyses using individual fixed effects, and find further support for the positive wealth-insurance correlation we document in cross-sectional analyses.

Overall, the evidence presented here is consistent with a subset of features that appear in classic models of insurance, such as diminishing risk aversion or, in the case of life insurance, a bequest motive. At the same time, our analyses suggest certain features to be added in future models of insurance choice, such as wealth-related differences in the distribution of shocks, or in market frictions such as access to liquidity or to information about financial products. A recent theory paper that goes in this direction is Rampini and Viswanathan (2019), which assumes wealth-related differences in insurance pricing, and as a result predicts that wealthier individuals are protected by insurance against a broader set of states of the world.

Our paper contributes to the household finance literature by providing novel evidence, based on a large administrative dataset, regarding the drivers of insurance-related choices. In doing so, we document an unexpected fact, in light of prior theory: namely, we find that insurance coverage is better for wealthier people. Another novel aspect of our paper is that our data allows us to examine several mechanisms which may explain this puzzling wealthinsurance correlation. Existing empirical evidence on the relationship between households' wealth or income and insurance demand in the US is often limited to aggregate data or largescale surveys. Showers and Shotick (1994) analyze households' expenditures on insurance premiums (aggregating across products) using data from the 1987 Consumer Expenditure Survey. They show that households with larger incomes spend more on insurance premiums. A similar relationship between incomes and premiums is documented in the context of life insurance by Fortune (1973) using aggregate US data from 1964 to 1971. Using data from the 1992 wave of the Health and Retirement Survey ("HRS"), Eisenhauer and Halek (1999) provide evidence that wealthier households purchase more life insurance coverage than poorer households. However, the authors restrict their sample to households purchasing life insurance and therefore only consider demand on the intensive margin. Fang and 
Kung (2012) likewise use data from the HRS to analyze life insurance purchase and lapsation decisions. They find that individuals with higher incomes are more likely to purchase life insurance. Their findings also suggest that negative income shocks may play a role in individuals' choosing whether to continue or lapse on existing life insurance policies.

A particularly important contribution to this literature is Armantier, Foncel, and Treich (2018), who examine the effect of wealth on insurance choices using survey data from approximately 1,800 participants in the Survey of Consumer Expectations, and focus on auto insurance coverage. The authors supplement the survey data from the US with administrative data on auto insurance coverage from clients of a French bank. We complement this paper by examining a larger sample of households $(60,000)$ and by relying on administrative data regarding several types of insurance contracts (life, homeowners, other property-related insurance), which include information about the dollar value of coverage limits - a dimension of insurance choice not examined in extant work due to lack of data.

Other notable papers that empirically examine insurance choices in the United States are Sydnor (2010), Barseghyan, Prince, and Teitelbaum (2011), Koijen, Van Nieuwerburgh, and Yogo (2016), and Jaspersen, Ragin, and Sydnor (2019). Sydnor (2010) examines households' choice of deductible for homeowners insurance. Barseghyan, Prince, and Teitelbaum (2011) likewise examine households' simultaneous choice of deductibles across both home and auto insurance and find that households' exhibit inconsistent risk preferences across their choice of deductibles, exhibiting greater risk aversion when choosing homeowners insurance relative to auto insurance policies. Jaspersen, Ragin, and Sydnor (2019) conduct a experiment and show that many structural models have poor predictive ability when it comes to explaining participants' insurance decisions over laboratory stakes. Similarly, Koijen, Van Nieuwerburgh, and Yogo (2016) use data from the HRS to document another insurance-related "puzzle" in the United States: households fail to rebalance their portfolios away from life insurance and toward annuities as they age. Their finding is consistent with the notion that "inertia" may play a role in households' insurance decisions (Sydnor (2010)). This suggests that insurance 
purchase decisions do not appear to be optimal for all households. The review in Cutler and Zeckhauser (2004) also indicates that at least in the context of life insurance, some households may make mistakes. Working-age individuals appear to underpurchase insurance, while older individuals appear to be overinsured, for example, by having life insurance in the absence of any dependents.

A different strand of the literature has examined the effects of having certain types of insurance on households' economic behavior. Using data from rural China, Cai (2016) finds that crop insurance increases households' crop production and borrowing. Also using data from rural China, Liu (2016) finds that access to health insurance increases households' investments in childhood education, but does not affect consumption. Autor, Kostøl, Mogstad, and Setzler (2019) finds that the receipt of disability insurance benefits reduces households' labor supply. There also exists a significant literature related to health insurance and its consequences. We do not study health insurance in this paper, as we do not have data about this type of coverage.

\section{Data}

We examine households' demand for insurance using administrative data provided by a financial services firm. The financial services firm offers both insurance and banking services to its customers. The data begin in September 2015, end in March 2019, and cover a sample of approximately 63,000 individuals with 2,500,000 person-month observations. For most of the analysis we will work with data aggregated at the person level, but we use monthly data when assessing within-person variables, such as the volatility of an individual's consumption or income. We also estimate regressions including individual-level fixed effects using the data at the person-month level.

The individuals in our sample were randomly selected from the universe of clients of this financial institution who maintained a checking or savings account at the financial 
services firm throughout the time period. For all individuals we have information about the monthly flows in and out of these accounts as well as the account balances. A third party firm employed by the financial institution categorizes transactions from the checking and savings accounts into various monthly payment types, such as credit card payments, mortgage payments, as well as auto or other loan payments. The dataset also includes the identity of each person's employer if that person is working. If an individual receives income from Social Security then that amount is labeled as such and is tabulated separately from labor income.

We also observe the balances of investment accounts for the subset of these individuals who use the wealth management arm of this financial services company. Our data do not contain the level of debts so we are unable to calculate net worth. We can however, observe whether or not the individual has a mortgage and some other types of debt (e.g., automobile or other installment loans) based on their monthly payments. The types of accounts for which we have balance information include checking accounts, savings accounts, certificates of deposit, tax-qualified and non-tax-qualified brokerage accounts, individual retirement accounts, mutual fund investments, and savings and annuity investments. We also have a measure of financial assets held by the individual that is calculated by the third party firm employed by this financial institution to provide supplementary information about the institution's clients; we use this measure of financial assets because it is available for all individuals regardless of whether or not they use the wealth management arm of the financial institution.

We observe individuals' insurance behaviors from two data sources: one source is the monthly information on income and insurance-related expenditures (based on observing transactions in these individuals' checking accounts at the financial institution providing the data), and the other contains information on financial assets and insurance coverage limits (based on information from the insurance arm of this institution). The expenditure data contain information on premium payments for life insurance and separately for "bun- 
dled" insurance, which we interpret as combined expenditures on property insurance such as homeowners or automobile policies.

The data on coverage limits separate six different insurance products: life (whole and term), homeowners, renters, automobile, valuable personal property ("VPP"), and fire insurance. We do not observe insurance deductibles nor do we observe the term length for life insurance policies. We observe premiums paid to a number of different insurers based on transactions via the checking and savings accounts; however, we only observe coverage limits for policies issued by the financial services provider. That is, if an individual purchases an insurance policy from an insurer other than the provider of our data, we observe the premiums paid but not the coverage limit for that policy.

In practice, insurance contracts can include various provisions that allow households' to purchase more insurance by means other than increasing coverage limits. For example, automobile insurance contracts can include "rental car coverage," which grants insureds the use of a rental car in the event of a loss while the insured vehicle is being repaired or replaced. This additional insurance coverage is reflected in higher premiums but not in an increased coverage limit. Unfortunately, we do not observe such contract features in our data.

Our data contain monthly snapshots of demographic information for each person in the sample, such as the zip code of residence, home ownership status, sex, age, marital status, and whether there are children in the household. The locations of the individuals in the sample span 50 states and the District of Columbia, for a total of 2,323 counties and 14,547 zip codes in the USA. Figure 1 illustrates the geographical dispersion of the people we study. ${ }^{3}$ Summary statistics regarding the individuals in the sample are presented in Table 1. To eliminate the influence of extreme outliers, we exclude from our regression analyses any individuals falling below the first percentile or above the 99th percentile in terms of dollar-denominated covariates (e.g. financial wealth or credit card spending).

\footnotetext{
${ }^{3}$ For $70 \%$ of individuals, we observe the complete set of 43 months (i.e. there are no gaps). We observe at least 42 out of 43 months for $90 \%$ of individuals in our data. Gaps are treated as missing data and are not otherwise accounted for. Some of these gaps occur due to individuals moving outside of the United States for a period of time. We exclude observations where the individual is living outside of the United States.
} 
We merge in other demographic variables related to the personal and geographic characteristics for individuals in our sample. Namely, we obtain information on house prices and the legal environment based on individuals' zip code of residence. We use the Zillow home value index ("ZHVI") for each month/zip code combination as our proxy for an individual's housing wealth, conditional on them being a homeowner. We use the Database of State Tort Law Reforms (Avraham (2019)) to examine legal standards across different states that may affect insurance demand. We discuss this database in additional detail below. For our analyses regarding life insurance, we obtain estimates for individuals' probability of death based on their sex and age from the National Vital Statistic System at the Centers for Disease Control and Prevention. Insurers are licensed and regulated at the state level, hence we use state fixed effects in our analyses to capture regulatory and other time-invariant differences across states.

To assess the representativeness of our sample, we compare it to the 2016 Survey of Consumer Finances ("SCF"). ${ }^{4}$ Compared to SCF respondents, individuals in our sample are more likely to be married, have children, and own a home. This is expected, as our sample by construction consists of individuals who actively use banking services of a major financial institution.

As shown in Table 2, the distribution of total income of individuals in our sample looks similar to that of the SCF; $54 \%$ of individuals in our sample lie within the 25th and 75 th percentiles of total income in the SCF, although the highest income percentiles in our sample are smaller than those of the SCF - likely due to the SCF's oversampling of wealthy individuals. However, in terms of earned income and financial wealth, individuals in our sample tend to resemble the middle of the SCF distribution. $70 \%$ of individuals have earned income within the middle $50 \%$ of the SCF earned income distribution and $95 \%$ of individuals have a financial wealth between the 25 th and 75 th percentiles of the SCF financial wealth

\footnotetext{
${ }^{4}$ We download the public release summary extract data available at https://www.federalreserve.gov/ econres/scf_2016.htm. Dollar-denominated values in the 2016 SCF are inflation-adjusted to 2019 dollars. We use all five implicates for each household along with the supplied survey weights to calculate summary statistics.
} 
distribution.

The insurance products studied here may also cover the same assets up to a particular limit. For example, homeowners and renters policies cover losses on certain durable goods such as furniture or electronic equipment. Individuals wishing to purchase additional coverage for these goods would purchase VPP policies.

\section{Results}

\subsection{Insurance coverage choices}

\subsubsection{Life insurance}

In Table 3 we investigate the factors that influence individuals' decision to have life insurance. We focus on term life insurance policies, as they constitute the vast majority (92\%) of life insurance policies we observe in the data. Moreover, while whole life insurance comes with investment related, tax-optimization features which make it difficult to study the insurance-related aspect of that product, term life insurance does not have these confounding features (Brown (2001)). ${ }^{5}$ Thus, we exclude individuals with whole life insurance from all life insurance-related analyses. In some countries (e.g. Portugal), mortgage lenders may require borrowers to obtain life insurance. However, mortgage lenders in the United States typically require that borrowers obtain homeowners insurance but do not require life insurance.

The dependent variable in Table 3 is an indicator for whether at any time during our sample the individual had a life insurance policy. We use Lewis (1989) as our theoretical framework for modeling life insurance demand. According to that model, the demand for life

\footnotetext{
${ }^{5}$ Insurance and financial advice websites (e.g. https://www.policygenius.com/life-insurance/ whole-life-insurance/ and https://www.ramseysolutions.com/insurance/whole-life-insurance) note the poor investment properties of whole life insurance and describe whole life policies as appropriate for higher income earners for tax purposes. Anagol, Cole, and Sakar (2017) provide evidence from India that whole life insurance policies are dominated by a combination of term life contracts and traditional savings accounts. Term life insurance is not given any tax-preferential treatment (see, e.g. https://www policygenius.com/life-insurance/is-life-insurance-taxable/).
} 
insurance depends on the level of consumption needed by the individuals benefiting from the policy, for example, spouses and children. In the Lewis (1989) framework, this consumption is the expected value of spending by these beneficiaries over the years left until the time when the children have sufficient income of their own. Life insurance is therefore used to guarantee that if the income of the individual is lost due to death, the same spending by beneficiaries would occur as in the case when the individual stayed alive and earned their income.

In our analysis, we assume that beneficiaries become financially independent when the insured person reaches age 65 , but other age thresholds lead to similar results. We calculate the net present value of the dependents or beneficiaries as the discounted value of a stream of annual credit card spending equal to that observed in the individual's financial records during our sample, over the number of years left until the person reaches 65 . In this calculation we use a discount rate $r$ equal to $1 \%$, but the choice of $r$ does not qualitatively change the results. Since consumption by beneficiaries also includes payments to creditors if the household has a mortgage or other consumer loans, we include among explanatory variables in Table 3 indicators for whether the household has such liabilities.

As shown in Table 3, the canonical predictions regarding the effect of the future expected spending of dependents on whether the person has life insurance are met in the data. A higher expected spending need of spouses or children leads to a significantly higher probability that an individual has life insurance, whether or not that expected spending captures the credit card expenditures we observe for this person on average in the years of the sample, or whether it captures mortgage payments or payments on other loans that the individual has during the sample, which most likely will need to continue to be paid in the event this individual dies. The estimated effects are both statistically significant and economically meaningful. Increasing the expected credit card expenditures by $\$ 100,000$ (i.e. increasing the value of the consumption stream to be insured) is associated with between a 0.43 to 0.72 percentage point increase in the probability of having life insurance depending on the 
specification. Simultaneously having a mortgage and a dependent is associated with an increased likelihood of having life insurance by between 13 and 14 percentage points. Having a dependent and non-mortgage loan (e.g. an automobile or installment loan) increases the likelihood of owning life insurance by between 2 and 4 percentage points. These effects are economically sizeable, given that the unconditional probability for a person in our sample to have term life insurance is $36 \%$ (see Table 1 ).

All else equal, the model in Lewis (1989) also predicts that having life insurance is more likely for a higher probability of death and a higher relative risk aversion coefficient. ${ }^{6}$ The first of these predictions can be verified in our data, as we are able to merge in for each individual in the sample the probability of death in the subsequent year, based on the person's age and gender. These probabilities are estimated by the CDC and represent averages across populations in the US that fall into each gender and age subcategories. These estimates, however, are not tailored based on the specific health status, for instance, of the particular individuals in our sample. As the theory predicts, we find a strong and positive correlation between the indicator variable for whether the person has life insurance and their probability of death in the next year (or, equivalently, a negative correlation between having life insurance and the person's expected remaining life span).

The result that does not conform to the Lewis (1989) theory is the positive and significant effect of the person's financial wealth on the probability that they have life insurance. Increasing the financial wealth of a household by $\$ 100,000$ is associated with approximately a 12 percentage point increase in their probability of owning life insurance. Housing wealth similarly is positively correlated with having life insurance (controlling for having a mortgage), with an increase of $\$ 100,000$ in the value of the home corresponding to a 0.93 percentage point increase in the probability of having term life insurance. The fact that wealth is a positive predictor of insurance coverage is a clear violation of the prediction in models of insurance

\footnotetext{
${ }^{6} \mathrm{~A}$ higher load also lowers the probability of having life insurance (Lewis (1989)). Here we assume that the load (i.e., the extent of monitoring costs) is similar across individuals, in the absence of any evidence to the contrary. To the extent that load values might be different for people residing in different parts of the US, the inclusion of state fixed effects in the analysis will control for these differences.
} 
choice, with the exception of Rampini and Viswanathan (2019). We will later investigate whether the pattern we document is driven by the assumptions in that model, specifically, the assumption that wealthier individuals face more favorable pricing of insurance and thus purchase more insurance than poorer individuals.

In Table 4 we examine the factors driving the life insurance coverage limit for individuals in our sample. The dependent variable is equal to the coverage limit for term life insurance policies held by each of these individuals. For those without such policies during the sample period, the dependent variable is equal to zero. We investigate the factors that have been proposed theoretically to drive the extent of life insurance in models such as Lewis (1989).

We find that for most of these factors, the data line up with the theory. An $\$ 1$ increase in the insured consumption stream is associated with a $\$ 0.04$ increase in the magnitude of life insurance coverage. Simultaneously having a dependent and mortgage is associated with increased life insurance holdings of $\$ 32,000$. The coefficient on the dependent/non-mortgage loan interaction is no longer significant, potentially indicating that non-mortgage loans drive the extensive margin of life insurance demand but not the intensive margin. Analogously, the sign on the coefficient estimate for an individual's probability of death switches from positive to negative. This reflects that life insurance ownership is more likely among older individuals but the magnitude of coverage decreases as individuals get older. ${ }^{7}$

However, we observe that wealth has the opposite effect on life insurance coverage limits relative to the theoretical predictions. Wealth, whether financial or housing-related, is a significant and positive predictor of the extent of life insurance coverage. In the entire sample (those who have no term life insurance and thus have a coverage limit of zero dollars, and those who have this product, for whom we know the coverage limit), we estimate that an increase of $\$ 1$ in their financial wealth corresponds to an increase of $\$ 0.68$ in the life

\footnotetext{
${ }^{7}$ We do not explicitly examine life cycle effects in the ownership of life insurance. But in unreported analyses, we use a series of age bin indicator variables and observe a "hump-shaped" pattern in terms of predicted life insurance coverage over the life cycle. See Koijen, Van Nieuwerburgh, and Yogo (2016) and Heimer, Myrseth, and Schoenle (2019) for examples of life cycle effects in households' insurance and savings decisions.
} 
insurance coverage limit. For housing wealth, a $\$ 1$ increase leads to an increase of $\$ 0.07$ in the coverage limit. Restricting the sample to just those people who have term life insurance (see the last column of Table 4 , the effects of a $\$ 1$ increase in wealth on the coverage limit are $\$ 1.51$ in the case of financial wealth, and $\$ 0.20$ in the case of housing wealth.

Figure 2 shows that the positive correlation between financial wealth and the extent of term life insurance coverage is present for all levels of financial wealth. Figure 2 is a binned scatter plot. Binned scatter plots are a convenient way to visualize regression results; they plot the residuals from two multivariate regressions to visualize the two-dimensional relationship between the dependent variable and independent variable of interest in a multivariate regression. In this figure, the residuals from a regression of term life insurance coverage on all explanatory variables except for financial wealth are plotted against the residuals from a regression of financial wealth on all other explanatory variables. The data are then grouped into one hundred bins and the mean of the residualized values are plotted against each other. ${ }^{8}$ The slope of a hypothetical least squares line plotted through Figure 2 is identical to the coefficient estimate on financial wealth in the multivariate regression results in the fourth column of Table 4. For an example of binned scatter plots used in a similar manner, see Chetty, Friedman, and Rockoff (2014).

In the analysis presented in that figure, just as in Table 4, we control for the insured dependents' expected spending, the insured person's own probability of death in the subsequent year, their housing wealth, and state fixed effects. We see that the correlation between life insurance coverage and financial wealth becomes smaller for higher levels of wealth, but it remains positive.

This pattern in Figure 2 sheds light on an alternative hypothesis for why those with lower wealth buy less life insurance - namely, that low wealth or low income individuals have access to certain types of social insurance (i.e., government-provided health insurance,

\footnotetext{
${ }^{8}$ We use the user-written Stata package binscatter 2 to automate the binned scatter plot procedure. Note that values of values of financial wealth on the horizontal axis may be negative when individuals have lower financial wealth than would be predicted (i.e. the residualized financial wealth values from the regression are negative), given their values of the other covariates in the fourth column of Table 4.
} 
food stamps, etc., that may help one's dependents to fare well if the bread winner in the family dies). If that were true, then these individuals would have less of a need to buy life insurance privately. This hypothesis, however, would imply that in Figure 2 we would observe a kink in the coverage-wealth relationship. Coverage should be zero or close to zero for the lowest levels of wealth, and increase steeply after some wealth level for which those social insurance benefits no longer are accessible. As the figure shows, however, there is no such kink in the functional form of life insurance coverage as a function of wealth.

\subsubsection{Property insurance}

We examine the drivers of participation in property-related insurance markets in Table 5. To a large extent, participation is determined by the legal environment. In the US, automobile owners must have car insurance. ${ }^{9}$ Home owners with a mortgage must have homeowners insurance. Other types of property-related insurance policies are available to consumers, but their uptake is not required by law. These include, for example, renters insurance, valuable personal property, boat, or fire insurance. For all property-related policies, the extent of coverage is determined by the consumer, even though the participation (e.g., whether one has homeowners insurance) is automatically decided by the legal environment. Hence, the variable of most interest is the coverage limit, rather than the decision to have coverage at all.

We first examine whether the individuals in our sample have any of these types of property-related policies, and then focus on homeowners insurance, as it is related to the asset that makes up the largest amount of net wealth of most US households. We later on examine the coverage limits for these policies. We limit our data to homeowners when estimating regressions that examine the coverage limit of homeowners insurance policies (i.e., in those regressions we exclude renters, as those policies do not apply to renters).

\footnotetext{
${ }^{9}$ There are two states with exceptions to this rule: New Hampshire and Virginia. In both of these states, automobile owners may forego insurance by paying a fee to the state government. We find that individuals in our sample residing in these states are not less likely to own auto insurance than residents of other states.
} 
In Table 6 we investigate whether the extent of coverage through homeowners insurance policies varies with wealth as in theoretical predictions. Prior models (see Schlesinger (2013) for a review) deliver clear predictions for the dollar value of coverage purchased. Specifically, all else equal, more insurance in absolute terms will be purchased by individuals faced with a higher probability of loss, higher risk aversion, and lower wealth (Schlesinger (1981)). Moreover, Mossin (1968) predicts that the fraction of the value of the home insured decreases with the ratio of non-housing related wealth to the value of the home. That is, if the insured asset does not represent much of the value of the overall wealth of the person, then it should be covered less through insurance. As the results in the table show, these empirical predictions are contradicted in the data. We find that individuals with higher financial wealth, and those with higher housing wealth, that is, people owning more expensive homes, will have higher coverage limits in their homeowners insurance policies. A $\$ 1$ increase in financial wealth is associated with a $\$ 2.25$ increase in the homeowners insurance coverage limit and a $\$ 1$ increase in the value of the home is associated with a $\$ 0.37$ increase in homeowners insurance coverage. Moreover, we find that people for whom their financial wealth is more substantial relative to their housing wealth have homeowners insurance policies that cover a higher fraction of the value of the home, which is opposite to the prediction coming from standard insurance models. Specifically, we find that a one percentage point increase in the ratio of financial wealth to housing wealth corresponds to an increase of 3.25 percentage points in the ratio of homeowners insurance coverage limit to the value of the home.

Figure 3 shows that the positive correlation between financial wealth and the extent of homeowners insurance coverage, controlling for the value of the home insured, is present for all levels of financial wealth. The correlation becomes smaller for higher levels of wealth, but it remains significantly greater than zero. As in the case of life insurance, the lack of a kink in the relationship between coverage and wealth suggests that the existence of social insurance benefits is not the driver of the positive correlation between these two variables. 


\subsection{Why are wealth and insurance coverage correlated?}

\subsubsection{Risk preferences}

Standard models of insurance or portfolio choice are built on the assumption of decreasing (absolute) risk aversion. While unlikely, it might be that in our data the wealthier are more risk averse, which would lead to empirical patterns of insurance choice opposed to what these models predict. We can test this explanation by examining the extent to which the individuals in our sample allocate their wealth to risky financial assets. We calculate the dollar amount of funds allocated by each individual to risk-free accounts, including savings, checking, and certificates of deposit. We also calculate the dollar amount of funds allocated by the same person to risky assets, through investment accounts offered by the financial institution providing the data. These accounts include regular brokerage accounts as well as tax-advantaged investment accounts, and contain investments in mutual funds, stocks, and bonds. We plot in Figure 4 the dollar amount (left panel) as well as the share (right panel) allocated to risky assets as a function of the total amount invested with this financial institution across safe and risky financial assets. It is clear from the figure that risk tolerance increases with wealth, as typically assumed by the theory, and documented by prior papers using survey or administrative data on portfolio allocations (see Guiso and Sodini (2013) for an overview of that literature).

Theoretically it has been shown that increased ambiguity aversion generally increases the demand for insurance (Alary, Gollier, and Treich (2013)), which is intuitive, as increases in ambiguity aversion have effects similar to increased pessimism. For ambiguity aversion to explain the positive wealth-insurance correlation we document in the data, it must be that ambiguity aversion increases with wealth. Baillon and Placido (2019) conduct an experiment investigating the wealth-ambiguity preferences relationship. They find no clear patterns in terms of increasing, decreasing, or constant ambiguity aversion attitudes toward wealth. While we do not have proxies in our data that measure ambiguity-related preferences, we 
rely on this prior work to argue that most likely our results are not driven by the wealthy being more ambiguity-averse than the less well off.

\subsubsection{Prices}

The model in Rampini and Viswanathan (2019) predicts that households' insurance expenditures decrease with income, because an increase in households' income under their assumed income process lowers the chance of occurrence of low income realizations in the future. It is important to keep in mind that wealth and income are the same concept in that model, where households use income in a period to consume or to buy insurance through Arrow-Debreu claims. In that setting, buying insurance is the only means to save for the future.

While the model is stark, it does rely on an assumption that seems reasonable: insurance for less likely future states should be cheaper. Since higher income individuals are assumed to have a lower chance of having a bad income shock in the future, getting insurance against those bad states should be cheaper for them than for people who are currently in a lower income state. In practice, this implies that insurers re-price insurance contracts in response to changes in insureds' income. So far there is no documented evidence in the literature that insurers take individuals' income into account when pricing life insurance policies, or other insurance products. Our data allows us to study whether prices for coverage in fact vary across people based on their income or wealth.

We investigate this pricing channel in the analysis in Table 7 and Table 8, for life and property insurance, respectively. The dependent variables in the OLS regressions in these tables are the prices (premiums) paid per dollar of coverage for life insurance, and for property insurance. The coefficient estimates on the coverage limits in Tables 7 and 8 are negative and significant. This is unsurprising, as part of the premiums paid by insureds are to cover monitoring and other fixed costs paid by the insurer, implying the potential for economies of scale with respect to coverage on individuals.

We find that, controlling for the amount and probability of loss insured, individuals 
with higher financial wealth pay higher prices for life insurance. A similar effect appears if instead of financial wealth we use the person's average annual income during the sample period: higher income individuals pay higher premiums for a certain level of life insurance coverage. This is opposite to the theoretical mechanism in Rampini and Viswanathan (2019).

A possible reason could be that wealthier individuals choose term life insurance policies that have longer term, that is, offer protection (for a given level of coverage limit) over more years than the policies secured by less well-off individuals. This would mechanically lead to the wealthier paying higher premiums per dollar of coverage. This scenario, however, is also one where the wealthier get more coverage, in the sense of the time frame covered, aside from the dollar limit of coverage. Hence, the data indicate one of two things: either the wealthy secure better coverage in terms of term, or they face higher prices compared to others. Neither one of these implications conforms to the classic theoretical models of insurance, but the mechanism in Rampini and Viswanathan (2019) might still be valid, if indeed the wealthy are insured for longer terms. ${ }^{10}$

\subsubsection{Volatility of consumption, income, or wealth processes}

Another possible reason why wealthier people get higher insurance coverage is that they might face more background risk. Perhaps the shocks to future consumption, income, or wealth faced by the wealthier households come from a wider distribution, compared to the shocks facing less wealthy households. As shown theoretically by Fischer (1973) and Rampini and Viswanathan (2019), increasing income volatility can increase the demand for insurance, whether it is life- or property-related. Similarly, consumption volatility may be higher for the wealthier, and hence insurance may be more important for these individuals. More generally, an independent, uninsurable background risk causes individuals to increase their demand for

\footnotetext{
${ }^{10}$ Analogously, wealthier individuals might purchase property and casualty insurance products with additional contract features such as rental car coverage while holding the coverage limit constant (and thus pay a higher premium). Again, this would suggest that the wealthier are better insured than the less wealthy, which is the puzzle we focus on in this paper.
} 
insurance (see e.g., Gollier and Pratt (1996)). ${ }^{11}$ The effects of non-independent background risk on households' demand for insurance naturally depends on the combination of preferences and the relationship between the insurable and background risks. See Schlesinger (2013) for further discussion on the effects of both independent and non-independent background risk on insurance demand.

We examine this volatility-related mechanism in the analysis in Table 9 and we find that in general, consumption, income, and wealth are more volatile in absolute terms (i.e., dollar amounts) for individuals with higher financial or housing wealth. We calculate annualized volatilities for each individual by taking the standard deviation of the monthly values (across time) and multiplying by the square root of 12 . The estimates in Table 9 show that a $\$ 1$ increase in financial wealth is associated with a $\$ 0.04$ increase in the annualized volatility of consumption. The wealthy also have more volatile income processes as well, a $\$ 1.00$ increase in financial wealth is associated with a $\$ 0.22$ increase in the annualized volatility of income. Therefore, it is possible that one driver of the positive link we observe between wealth and insurance coverage is the increased background risk of more affluent households.

To investigate this further, we add these measures of background risk as additional explanatory variables in our prior models where the dependent variable is the extent of life or homeowners insurance coverage. This analysis is presented in Table 10. As predicted by theory, the volatility of consumption or income are positive and significant predictors of insurance coverage limits. That is, people faced with more background risk have more insurance coverage. As shown in Figure 5, these results are obtained throughout the entire distribution of consumption or income volatility. However, while controlling for background risk changes slightly the effects of financial or housing wealth on insurance coverage limits relative to those estimated in our baseline models in Table 4 and Table 6 , these effects remain positive, statistically and economically significant. Therefore, our evidence indicates

\footnotetext{
${ }^{11}$ Risk aversion is not sufficient for this result. For example, insurance demand with CARA preferences is unchanged by introduction of an independent background risk. However, a sufficient condition is so-called "standard risk aversion," which is related to prudence (the third derivative of the utility function). CRRA preferences, for example, exhibit "standard risk aversion."
} 
that the higher background risk faced by wealthier individuals can not by itself explain why the wealthier get more insurance coverage.

\subsubsection{Legal risk}

It is also possible that the probability or extent of loss for any insured asset - be it future income (through life insurance), or property (through homeowners insurance, for example) may be higher for wealthier individuals. In the case of property-related risk, this may be due to the legal environment. In some U.S. states it is easier than in others for an individual to be subject a costly lawsuit if somebody gets injured on this person's property, for example. This is why many homeowners insurance policies in the U.S. cover not only the cost of the structure of the home, but also expenses incurred in such lawsuits. Therefore, the wealthy may have to purchase larger amounts of insurance because they may be liable for payments commensurate with the value of their total wealth, and not necessarily limited to the value of the property insured. In other words, the distribution of potential losses depends on wealth.

Note that for life insurance, however, this legal risk channel is unlikely to apply, as the probability of death is unlikely to increase with the person's wealth. If anything, as shown by Chetty, Stepner, Abraham, Lin, Scuderi, Turner, Bergeron, and Cutler (2016), higherincome individuals have longer life expectancies, which should lower the demand for life insurance. Hence, we focus on demand for homeowners and other property and casualty insurance products when we examine the legal risk channel.

While we cannot directly observe the correlation between individuals' financial wealth and their propensity to be sued, we can examine the legal risk mechanism by examining the connection between wealth and insurance demand in different litigation risk regimes. If legal risk increases with wealth and drives homeowners insurance purchases, the relationship between wealth and insurance coverage should be stronger in higher risk jurisdictions relative to lower risk jurisdictions.

To investigate this legal risk channel, we use the Database of State Tort Law Reforms 
("DSTLR", Avraham (2019)). The DSTLR was developed for the purpose of examining the effects of tort law on medical malpractice insurance. The database contains information on eleven different aspects of tort law for each state in a particular year; we focus on two aspects that may affect the expected losses due to litigation. The first of these two aspects are rules governing the maximum amount that can be awarded to a plaintiff in litigation through caps on damages. The second concerns the percentage of a damages award can be shared with plaintiffs' attorneys (a "contingency fees"). ${ }^{12}$ We combine these two aspects of tort law with an indicator variable measuring whether or not a particular state has an unlimited homestead exemption. An unlimited homestead exemption ensures that a defendant's home is off-limits in terms of covering the damages award in a lawsuit. ${ }^{13}$ There are seven such states in the USA. We then split the states into those that have above-average litigation risk and those with below-average litigation risk. ${ }^{14}$ Intuitively, individuals living in states with more litigation risk should, all else equal, seek higher insurance coverage, especially if they have higher wealth, which could increase the chance of facing a lawsuit.

In Table 11 we examine the wealth-insurance relationship in a series of regressions where the dependent variable is the amount of homeowners insurance, or overall property insurance purchased by individuals. The coefficient estimates in columns 1 and 3 indicate that living in a state with high litigation risk is associated with a $\$ 45,000$ increase in homeowners insurance coverage and a $\$ 55,000$ increase in coverage across all property and casualty insurance

\footnotetext{
${ }^{12}$ Contingency fee rules often take the form of lowering the portion of a damages' award that can be given to the attorney at various thresholds. By way of example, the rule governing contingency fees in Illinois (effective until 2013) specified that contingency fees may not exceed $33 \%$ of the first $\$ 150,000 ; 25 \%$ of the next $\$ 850,000$; and $20 \%$ of any amount over $\$ 1,000,000$. Such contingency fee rules reduce the marginal returns to effort on the part of plaintiffs' attorneys and thus may be expected to lower expected payouts by insurers.

${ }^{13}$ Mahoney (2015) studies such exemptions in the context of health insurance, finding that the ability to shield asset values and discharge medical debt in bankruptcy affects insurance decisions, lowering demand for insurance when agents can shield assets with bankruptcy exemptions.

${ }^{14}$ In our sample, the average individual lived in a state with two of the three aspects of litigation risk. Therefore we split the sample into whether or not a person lives in a state with all three elements of increased legal risk, or only one or two (all states had at least one "riskier" aspect of tort law or no homestead exemption). Our conclusions remain the same under alternate definitions of legal risk using other aspects of the DSTLR such as caps on damages related to pain and suffering or so-called "comparative fault" tort reforms.
} 
products in our data. In columns 2 and 4, we find a positive and significant interaction term between a person's financial wealth and the high legal risk indicator; an additional $\$ 1.00$ of financial wealth is associated with an increase of $\$ 2.15$ in homeowners insurance in a low-risk state, versus $\$ 2.70(\$ 2.15+\$ 0.55)$ in a high-risk state. The significance of the interaction term suggests that litigation risk is a driver of individuals' demand for homeowners or property insurance. We interpret this finding as suggestive evidence that legal risk drives some of the demand for property and casualty insurance, though perhaps only for individuals in the upper tail of the wealth distribution.

\subsubsection{Liquidity constraints}

It may be that individuals, particularly those with low income and low financial wealth, are liquidity constrained and are unable to afford insurance due to other financial commitments. Generally, the prior literature has found that liquidity constraints reduce household spending (e.g., Zeldes (1989); Johnson, Parker, and Souleles (2006); Baker and Yannelis (2017)), particularly for households with low financial sophistication (Parker (2017)). ${ }^{15}$ Buying insurance, however, is not simply spending. Rather, it is a risk-mitigation strategy used for consumption smoothing. As a result, as shown theoretically in Gollier (2003) and Ericson and Sydnor (2018), insurance products would be most sought after by individuals who are most liquidity constrained (particularly products involving the smooth payment of small premiums over time rather than the payment of one large lump sum premium).

Empirically we find that in fact those who are most liquidity constrained have lower insurance coverage. We measure liquidity constraints for each individual using two separate measures. The first measure of liquidity constraints is what we refer to as the credit ratio, calculated as the monthly expenditures on the credit card provided by the financial insti-

\footnotetext{
${ }^{15}$ While important, liquidity constraints are not the only factor impacting spending responses to income or other shocks. Prior work has provided evidence that spending decisions are also driven by present bias (Olafsson and Pagel (2018), Ganong and Noel (2019)), mental accounting, anchoring, or other heuristics (Baugh, Ben-David, Park, and Parker (2021); Keys and Wang (2019); Baugh and Wang (2018)), as well as by the lack of financial literacy (Jørring (2020)).
} 
tution divided by the credit limit on the card. ${ }^{16}$ The second measure, which we refer to as the debt-to-income ratio, is calculated as the ratio of short-term debt, which is the sum of monthly mortgage, auto, and installment loan payments, to total income.

Figure 6, as well as Table 12 show generally that credit usage as well as the debt-to-income ratio decrease with financial wealth. For housing wealth we observe that for those in the upper $90 \%$ of the distribution of wealth there is generally a decreasing relationship between housing wealth and credit usage. The debt-to-income ratio increases with housing wealth, controlling for financial wealth. Since our housing wealth measure for homeowners is the Zillow home value index, without accounting for the outstanding principal on the mortgage on the house, this relationship can simply capture the fact that mortgage payments are larger if, all else equal, the home is worth more. But it may also be the case that leverage is higher for those with more assets in place. We examined this by looking at the universe of people who do not have a mortgage on the house, or who are renters, and among those individuals, we continue to observe a positive and significant correlation between housing wealth and the debt-to-income ratio (albeit about 50\% smaller in magnitude).

While these results show that wealth and liquidity constraints are related, the regression models in Table 13 indicated that even after controlling for a person's credit use ratio or their the debt-to-income ratio, we continue to observe a strong and positive correlation between wealth (financial or housing-related) and the extent of life insurance and homeowners insurance coverage. The estimates in Table 13 indicate that after controlling for the credit usage as a measure of liquidity constraints, a $\$ 1.00$ increase in financial wealth is associated with a $\$ 0.67$ increase in life insurance coverage (as opposed to $\$ 0.68$ in Table 4 , column 4 ) and a $\$ 2.22$ increase in homeowners insurance coverage (as opposed to $\$ 2.25$ in Table 6 , column 1). In other words, liquidity or the lack thereof, can not explain away the puzzling

\footnotetext{
${ }^{16}$ Over $95 \%$ of individuals utilize credit cards issued by the financial institution providing the data at some point in our sample. The median monthly credit card expenditure is approximately $\$ 1,600$. We are unable to observe whether or not an individual carries a balance on the credit card from month-to-month and therefore cannot distinguish between individuals who rollover credit card debt versus those who simply spend close to the limit in each month.
} 
fact that wealthier people are better insured.

That being said, our liquidity proxies impact coverage limits, as hypothesized. The credit use ratio negatively predicts insurance coverage limits, as expected if liquidity constraints impacted people's ability to pay their insurance premiums. The debt-to-income ratio is positively correlated with the coverage limits. This is expected, as debt include mortgage payments. A higher mortgage payment, also else equal, increases this ratio, but it also increases the need for life insurance (as dependents need to continue to make mortgage

payments if the insured were to die), and for homeowners insurance (as a higher mortgage payment likely means a more expensive home, which our zip code Zillow home valuation will not capture). While the latter may be a mechanical result, the former - i.e., people with a higher debt-to-income ratio have higher life insurance coverage - may be an illustration of the theoretical insight from Gollier (2003) and Ericson and Sydnor (2018) that insurance can be particularly valuable for people concerned about future access to liquidity. In the case of life insurance, a policy holder whose household faces a large mortgage or other debt relative to that household's income (most of which may be generated by the policy holder), may be concerned that in the event of their death, the dependents' debt burden will be too large relative to their income at that time. In other words, concerns about the dependents' future access to funds or liquidity needed to make debt payments may overcome concerns about the current access to liquidity of the household (i.e., the policy holder and their dependents).

\subsubsection{Financial knowledge}

It is possible that wealthier individuals have more insurance coverage because they are more aware of the existence of insurance products. The effects of financial acumen on household economic choices have been studied by prior work (see the review in Gomes, Haliassos, and Ramadorai (2020)), with newer research showing a causal effect of exposure to certain financial products on choices. For example, people with more experience with banking services early in life have better consumer credit outcomes years later (Brown, Cookson, and 
Heimer (2019)), while people with more access to information regarding financial markets subsequently have better exposure to equities (Haliassos, Jansson, and Karabulut (2020)).

Here, we will use education as our proxy for financial knowledge, specifically, for knowledge regarding insurance products. In our data, we know whether or not a person has a college degree for about a third of the sample. Education is not a personal characteristic that generally has to be shared by a consumer when they open a checking account or a brokerage account, for example. However, some of the clients of the institution providing the data revealed their education level. We split the sample into individuals without a college degree, those for whom the education level is unknown, and those who have a college degree or post-college education.

We investigate whether controlling for education, the positive correlation between wealth and insurance coverage diminishes or disappears. As shown in the regression results in Table 14 , this is not the case. We observe that, all else equal, people who have a college degree have higher coverage limits for both term life insurance (an increase of approximately $\$ 45,000$ ) and homeowners insurance products (an increase of approximately $\$ 105,000$ ). This suggests that education helps people be aware of, or be interested in, using these types of products. Another interpretation, however, is that higher education is a proxy for higher expected future earnings. In the context of life insurance, this may correlate with the dependents having higher expected consumption that needs to be insured through this product. In the context of homeowners insurance, this may mean the insured has more future wealth to protect, from, say, litigation by people who have an accident on this individual's property. In other words, education could proxy for financial literacy, but may also correlate with other factors that would make a person choose a higher level of coverage. That being said, irrespective of what education captures, the results in Table 14 show that controlling for whether a person has a college degree or not does not eliminate the strong and positive correlation between financial or housing wealth and the extent of insurance coverage across both life and homeowners insurance. 
Related to the financial literacy driver of insurance purchase decisions, it is possible that the less wealthy do not trust financial products or institutions as much as their better-off counterparts, and thus do not purchase products like insurance. It is also possible that insurance products are being advertised more to those who are wealthier, and thus there could be supply-side reasons for why these individuals have better insurance coverage. While these are important potential mechanism at play in households' decisions regarding insurance purchases, we can not test them with the data available to us at this point.

\subsubsection{Subjective beliefs}

Differences in subjective beliefs regarding the probability of insurable losses between poorer and wealthier individuals may result in different coverage decisions. For example, the wealthy may purchase more life insurance coverage because they believe that they are more likely to die. Puri and Robinson (2007) develop a measure of individual subjective optimism, defined as the difference between individuals' expected longevity versus longevity as predicted by actuarial life tables. The authors show that this measure of subjective optimism is positively correlated with wealth. Accordingly, the wealthy should be less likely to purchase life insurance based on their subjective beliefs. ${ }^{17}$ Therefore, it is improbable that wealthier people in our sample have higher insurance coverage because of more pessimistic subjective beliefs about future shocks, relative to the less wealthy individuals.

\subsubsection{Employer benefits}

Another potential reason why wealthier people buy more insurance is that they may not have generous benefits through their job. For example, wealthier individuals may be more likely to be self-employed, and thus may not have, say, access to employer-provided life insurance or assistance in case of negative financial shocks such as damage to their home. While intuitively we think of wealthier people as having better benefits through their job

\footnotetext{
${ }^{17}$ We are not aware of any empirical evidence connecting wealth and subjective beliefs for insurable events other than death (e.g., for the probability of a home insurance claim).
} 
compared to their less well-off peers, it is worth investigating if in our data this intuition may not be correct.

The individuals in our sample work for over 40,000 unique employers. The employer most represented in the sample is the U.S. federal government. About one third of individuals in

our sample receive labor income from this employer at some point during the four years of the sample. Hence we can conduct a within-employer analysis of the relationship between wealth and insurance coverage. Therefore, in this analysis we keep constant the benefits (such as group life insurance) that employees get through their job, and we examine whether wealth continues to positively predict the extent of insurance purchased by these individuals privately.

In Table 15 we observe that the positive and significant correlation between wealth and insurance coverage continues to persist, even when we examine the subsample of individuals who are US federal government employees. This is shown in the first column of the table for the case of life insurance coverage limits, and in the second column of the table for the case of homeowners insurance. The last two columns of the table conduct the same analyses, but for the individuals in the sample who are not employed by the US federal government. Interestingly, controlling for all the factors considered in the main analyses in Tables 4 and 6 , the correlation between financial wealth and either life or homeowners insurance coverage limit is greater in magnitude (by a factor of about 40\%) in the sample of people who do not have jobs with the federal government. A possible reason is that certain factors that may drive insurance demand, like background risk, could be different for people working in non-government vs. government jobs.

\subsubsection{Within-person analysis}

So far we have documented a cross-sectional pattern: people who have more wealth during the 43 months of our sample have more extensive insurance coverage, a result which contradicts classic models of insurance choice. We then attempted to explain this puzzling result by 
accounting in our cross-sectional regressions for channels not accounted for in these theories, including wealth-related differences in risk preferences, pricing, background risk, litigation risk, liquidity constraints, financial acumen, or employer-provided benefits. We continued to document that wealthier people have more insurance coverage even after accounting for these other mechanisms. However, it is possible that there is some other omitted variable that positively correlates with both wealth and a person's insurance demand that is not captured by the channels we examined so far. We investigate this possibility by including individual fixed effects and re-estimating our models for having life insurance, as well as for the extent of life insurance and homeowners insurance coverage. Here we make use of the fact that our raw data is at the person-month level.

Measuring variables such as financial wealth or the consumption needs of dependents based on monthly data comes with more noise than measuring these variables for one person by averaging across all the months when the individual is in the sample. This can naturally lead to attenuation in coefficients estimated in a person fixed-effects specification using person-month data, rather than in a cross-sectional analysis at the person level. Therefore, it is possible to find different coefficients in the fixed-effects specification. That being said, if even when accounting for individual fixed effects we continue to see a significant and positive correlation between wealth and insurance coverage, this will tell us that the puzzle we have documented is not driven by an omitted variable that is a fixed characteristic of an individual.

The results in Table 16 show that, even accounting for person fixed effects, as well as for the controls used in the main regressions, we still estimate a positive and significant effect of wealth on insurance coverage. Specifically, as indicated by the results in the first column, increasing a person's financial wealth by $\$ 100,000$ in a given month leads to a 2 percentage point increase in the probability that in that month the person has a life insurance policy. In the cross-sectional analysis in Table 3 we had obtained that if a person had $\$ 100,000$ more financial wealth than another person, on average across the 43 months in the sample, 
that would have corresponded to the first individual having a 12 percentage points higher probability of having life insurance relative to the second individual, at some point during the sample period. The estimate in the second column (0.05) shows that within-person, a $\$ 1$ increase in financial wealth leads to an increase of 5 cents in the life insurance coverage limit observed in a given month. The corresponding coefficient in the cross-sectional analysis in Table 4 was $\$ 0.68$, an order of magnitude higher than the $\$ 0.05$ estimated in the person fixed effects specification. For the homeowners insurance, the effect of a $\$ 1$ increase in financial wealth within-person is an increase of 30 cents in the coverage limit, smaller than the $\$ 2.25$ increase estimated in the cross sectional results in Table 6. Finally, in the last column of Table 16 we find that a 1 percentage point increase in the ratio of a person's financial wealth to housing wealth leads to a 0.58 percentage point increase in the fraction of the home value covered by the homeowners insurance policy. The cross-sectional effect in Table 6 was estimated to be 3.25. In terms of the effects of within-person changes in housing wealth on insurance coverage, in all specification in Table 16 we obtain positive and significant estimates, similar in terms of magnitude to those observed in our cross-sectional analyses.

How do we interpret the estimates of the effects of wealth on insurance coverage that we obtain from these within-person regressions? First, all of these estimates are positive, economically meaningful, and statistically significant. This suggests that omitted, fixed individual characteristics can not explain the puzzling result that wealthier people in our sample are better insured. Second, the fact that the effects of financial wealth on insurance coverage are smaller when using a person fixed effects specification than when conducting cross-sectional analyses indicates that there is something different across people who are wealthier versus those who are not, and as a result, the wealthier are better insured. In analyses conducted in earlier subsections, we have examined specific such differences (e.g., education, background risk, etc.). The coefficient differences between the individual fixed effects specifications and the cross-sectional ones suggest that more work needs to be done to identify exactly which individual characteristics associated with wealth are important for 
insurance coverage decisions.

\section{Implications and conclusion}

While there exist a significant theoretical literature focused on households' insurance purchase decisions, empirical evidence, especially based on administrative data, is scarce when it comes to life or property-related insurance. Insurance products are present in the financial portfolio of the majority of households, yet it has remained unclear how people make insurance coverage decisions in practice. Here we use a rich administrative dataset from a large financial institution to test one of the most salient theoretical predictions about the drivers of insurance choices.

Specifically, we test the theoretical prediction that in a setting where risk aversion diminishes with wealth, individuals who are wealthier will be more likely to self-insure relative to those less well-off. The preference for self-insurance is driven by the fact that insurance products come with a load, or monitoring and other costs that cause the prices paid by households for these products to be actuarially unfair. We document a stark pattern that contradicts the theory. Whether we measure wealth by the value of financial assets, or by the value of the homes individuals own, we find that life insurance coverage as well as property insurance coverage increase with wealth, controlling for the value of the insured asset.

We investigate several mechanisms that could explain this puzzling finding, including differences by wealth in terms of risk preferences, prices offered by insurers, background risk, litigation risk, liquidity constraints, financial literacy, and employer-provided benefits. While we find evidence that these mechanisms explain some of the puzzling positive correlation between wealth and insurance coverage, even after accounting for these factors, we continue to observe that wealthier people in our sample of 63,000 people are better insured. Moreover, in specifications using approximatively 2,500,000 person-month observations, where we include person-level fixed effects, we again estimate a positive and significant correlation between 
wealth and insurance coverage.

These results suggest more work is needed to understand households' insurance choices. While here we examine several potential mechanisms, the evidence suggests that there are other wealth-related reasons why those better-off financially also have better insurance coverage, against the predictions of theoretical models written on the topic of insurance demand over several decades. Identifying these other reasons is a fruitful avenue for future work using household-level or other micro data. From a more macroeconomics-oriented perspective, it is possible that the wealth-related differences we observe in terms of insurance coverage might vary with the business cycle, or may lead to heterogeneity in the effects of macroeconomic shocks across different segments of the population. Our data only covers four years, which do not include recessions, and therefore we can not investigate these predictions. From a policy perspective, it also remains to be understood whether the wealthier households are over-insured, or the less wealthy ones are under-insured. For example, it is important to determine whether the provision of insurance products by financial institutions varies by wealth, such that the less well-off households do not have the same access to such products as their wealthier counterparts. If there is a preferential supply of insurance products to the wealthy, who theoretically are those who need these products the least, this could imply that the less well-off households are underserved by insurance companies and will not be protected when negative shocks arrive in the future. We hope that future work can address these questions related to insurance coverage, which is a critical aspect of the financial health of households. 


\section{References}

Alary, D., C. Gollier, and N. Treich (2013). The Effect of Ambiguity Aversion on Insurance and Self-Protection. The Economic Journal 123(573), 1188 - 1202.

Anagol, S., S. Cole, and S. Sakar (2017). Understanding the Advice of CommissionsMotivated Agents: Evidence from the Indian Life Insurance Market. Review of Economics and Statistics 99(1), 1-15.

Armantier, O., J. Foncel, and N. Treich (2018). Insurance and Portfolio Decisions: A Wealth Effect Puzzle. Working paper.

Autor, D., A. Kostøl, M. Mogstad, and B. Setzler (2019). Disability Benefits, Consumption Insurance, and Household Labor Supply. American Economic Review 109(7), 2613 2654.

Avraham, R. (2019). Database of State Tort Law Reforms (6.1). Working paper.

Baillon, A. and L. Placido (2019). Testing Constant Absolute and Relative Ambiguity Aversion. Journal of Economic Theory 181, 309 - 332.

Baker, S. and C. Yannelis (2017). Income Changes and Consumption: Evidence from the 2013 Federal Government Shutdown. Review of Economic Dynamics 23, 99 - 124.

Barseghyan, L., J. Prince, and J. Teitelbaum (2011). Are Risk Preferences Stable Across Contexts? Evidence from Insurance Data. American Economic Review 101(2), 591 631.

Baugh, B., I. Ben-David, H. Park, and J. Parker (2021). Asymmetric Consumption Smoothing. American Economic Review 111(1), 192 - 230.

Baugh, B. and J. Wang (2018). When Is It Hard To Make Ends Meet? Working paper.

Brown, J. (2001). Are the Elderly Really Over-Annuitized? New Evidence on Life Insurance and Bequests. In D. Wise (Ed.), Themes in the Economics of Aging, Chapter 3, pp. 91-126. University of Chicago Press. 
Brown, J. R., J. A. Cookson, and R. Heimer (2019, December). Growing Up Without Finance. Journal of Financial Economics 134(3), 591-616.

Cai, J. (2016). The Impact of Insurance Provision on Household Production and Financial Decisions. American Economic Journal: Economic Policy 8(2), $44-88$.

Chetty, R., J. Friedman, and J. Rockoff (2014). Measuring the Impacts of Teacher II: Teacher Value-Added and Student Outcomes in Adulthood. American Economic Review $104(9), 2633-2679$.

Chetty, R., M. Stepner, S. Abraham, S. Lin, B. Scuderi, N. Turner, A. Bergeron, and D. Cutler (2016). The Association Between Income and Life Expectancy in the United States, 2001-2014. JAMA 315(16), 1750 - 1766.

Cutler, D. M. and R. Zeckhauser (2004). Extending the Theory to Meet the Practice of Insurance. Brookings-Wharton Papers on Financial Services 1, 1-53.

Eisenhauer, J. and M. Halek (1999). Prudence, Risk Aversion, and the Demand for Life Insurance. Applied Economic Letters 6(1), 239 - 242.

Ericson, K. and J. Sydnor (2018). Liquidity Constraints and the Value of Insurance. NBER Working Paper No. w24993.

Fang, H. and E. Kung (2012). Why Do Life Insurance Policyholders Lapse? The Roles of Income, Health and Bequest Motive Shocks. NBER Working Paper 17899.

Fischer, S. (1973). A Life Cycle Model of Life Insurance Purchases. International Economic Review 14(1), 132-152.

Fortune, P. (1973). A Theory of Optimal Life Insurance: Development and Test. The Journal of Finance 28(3), 587-600.

Ganong, P. and P. Noel (2019). Consumer Spending during Unemployment: Positive and Normative Implications. American Economic Review 109(7), 2383-2424. 
Gollier, C. (2003). To Insure or Not to Insure? An Insurance Puzzle. The Geneva Papers on Risk and Insurance Theory 28(1), 5-24.

Gollier, C. and J. Pratt (1996). Risk Vulnerability and the Tempering Effect of Background Risk. Econometrica 64(5), 1109 - 1123.

Gomes, F., M. Haliassos, and T. Ramadorai (2020). Household Finance. Journal of Economic Literature, forthcoming.

Guiso, L. and P. Sodini (2013). Household Finance: An Emerging Field. In G. Constandinides, H. Milton, and R. Stulz (Eds.), Handbook of the Economics of Finance. Elsevier Science.

Haliassos, M., T. Jansson, and Y. Karabulut (2020, February). Financial Literacy Externalities. Review of Financial Studies 33(2), 950-989.

Heimer, R., K. Myrseth, and R. Schoenle (2019). YOLO: Mortality Beliefs and Household Finance Puzzles. The Journal of Finance 74(6), 2957 - 2996.

Jaspersen, J., M. Ragin, and J. Sydnor (2019). Predicting Insurance Demand from Risk Attitudes. Working Paper.

Johnson, D., J. Parker, and N. Souleles (2006). Household Expenditure and the Income Tax Rebates of 2001. American Economic Review 96(5), 1589-1610.

Jørring, A. (2020). Financial Sophistication and Consumer Spending. Working Paper.

Keys, B. and J. Wang (2019). Minimum Payments and Debt Paydown in Consumer Credit Cards. Journal of Financial Economics $131(3), 528$ - 548.

Koijen, R., S. Van Nieuwerburgh, and M. Yogo (2016). Health and Mortality Delta: Assessing the Welfare Cost of Household Insurance Choice. The Journal of Finance 71 (2), $957-1010$.

Lewis, F. (1989). Dependents and the Demand for Life Insurance. American Economic Review $79(3), 452-467$. 
Liu, K. (2016). Insuring Against Health Shocks: Health Insurance and Household Choice. Journal of Health Economics 46, 16-32.

Mahoney, N. (2015). Bankruptcy as Implicit Health Insurance. American Economic Review $105(2), 710-746$.

Mossin, J. (1968). Aspects of Rational Insurance Purchasing. Journal of Political Economy $76(4), 553-568$.

Olafsson, A. and M. Pagel (2018). The Liquid Hand-to-Mouth: Evidence from Personal Finance Management Software. Review of Financial Studies 31(11), 4398-4446.

Parker, J. (2017). Why Don`t Households Smooth Consumption? Evidence from a $\$ 25$ Million Experiment. American Economic Journal: Macroeconomics 9(4), 153-183.

Puri, M. and D. Robinson (2007). Optimism and Economic Choice. Journal of Financial Economics 86(1), 71-99.

Rampini, A. and S. Viswanathan (2019). Financing Insurance. Working Paper.

Schlesinger, H. (1981). The Optimal Level of Deductibility in Insurance Contracts. The Journal of Risk and Insurance 48(3), 465-481.

Schlesinger, H. (2013). Theory of Insurance Demand. In G. Dionne (Ed.), Handbook of Insurance, Chapter 7, pp. 167 - 184. New York: Springer.

Showers, V. and J. Shotick (1994). The Effects of Household Characteristics on Demand for Insurance: A Tobit Analysis. The Journal of Risk and Insurance 61 (3), 492-502.

Sydnor, J. (2010). (Over)insuring Modest Risks. American Economic Journal: Applied Economics 2(4), 177-199.

Zeldes, S. (1989). Consumption and Liquidity Constraints: An Empirical Investigation. Journal of Political Economy 97(2), 305-346. 
Sample Coverage

Sep 2015 - Mar 2019

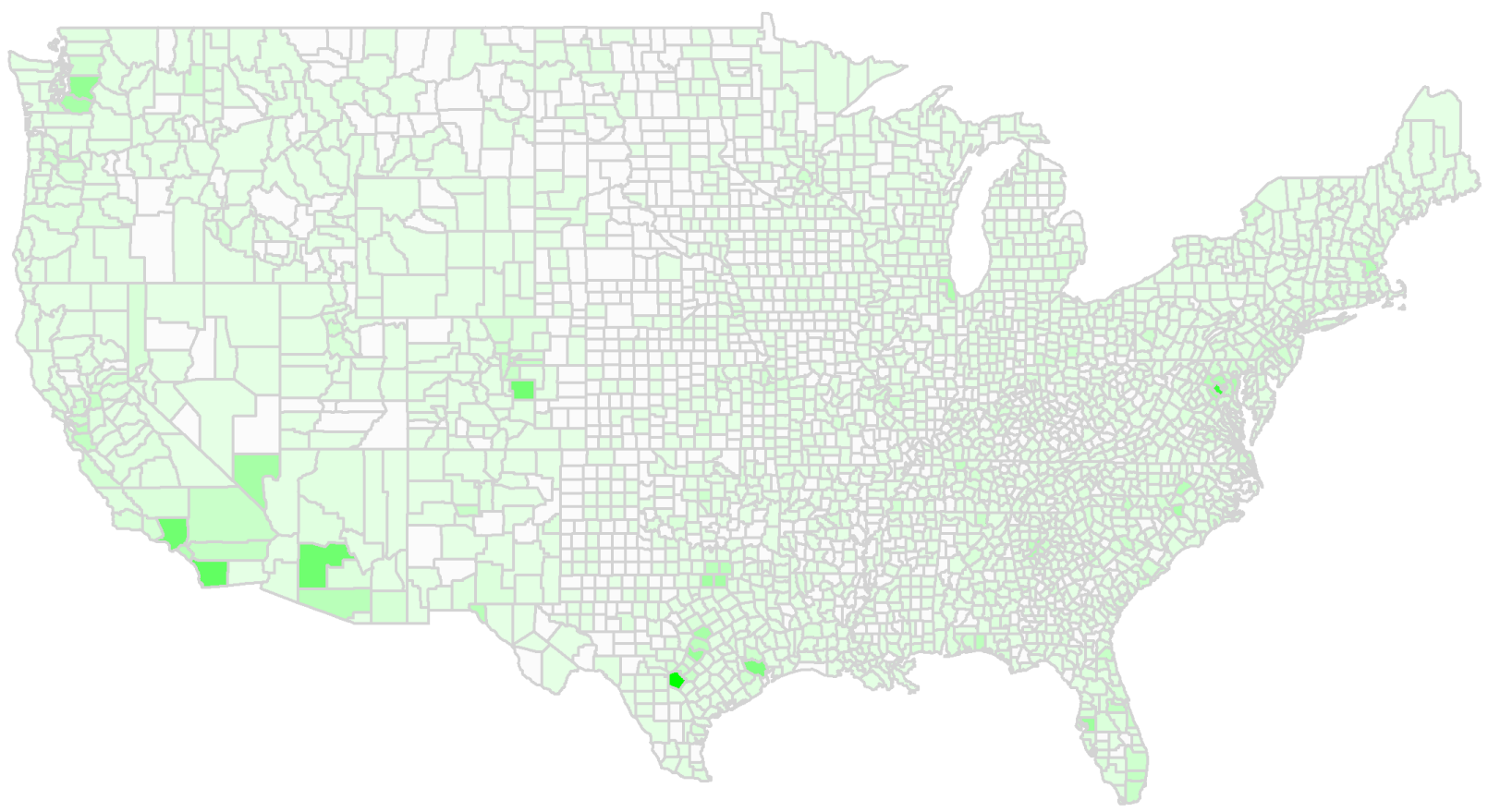

Figure 1: Sample distribution across the United States. This figure shows the location of individuals in our sample. Counties in green have at least one individual. Locations with high representation include San Antonio, TX, Washington, DC, and San Diego, CA. 


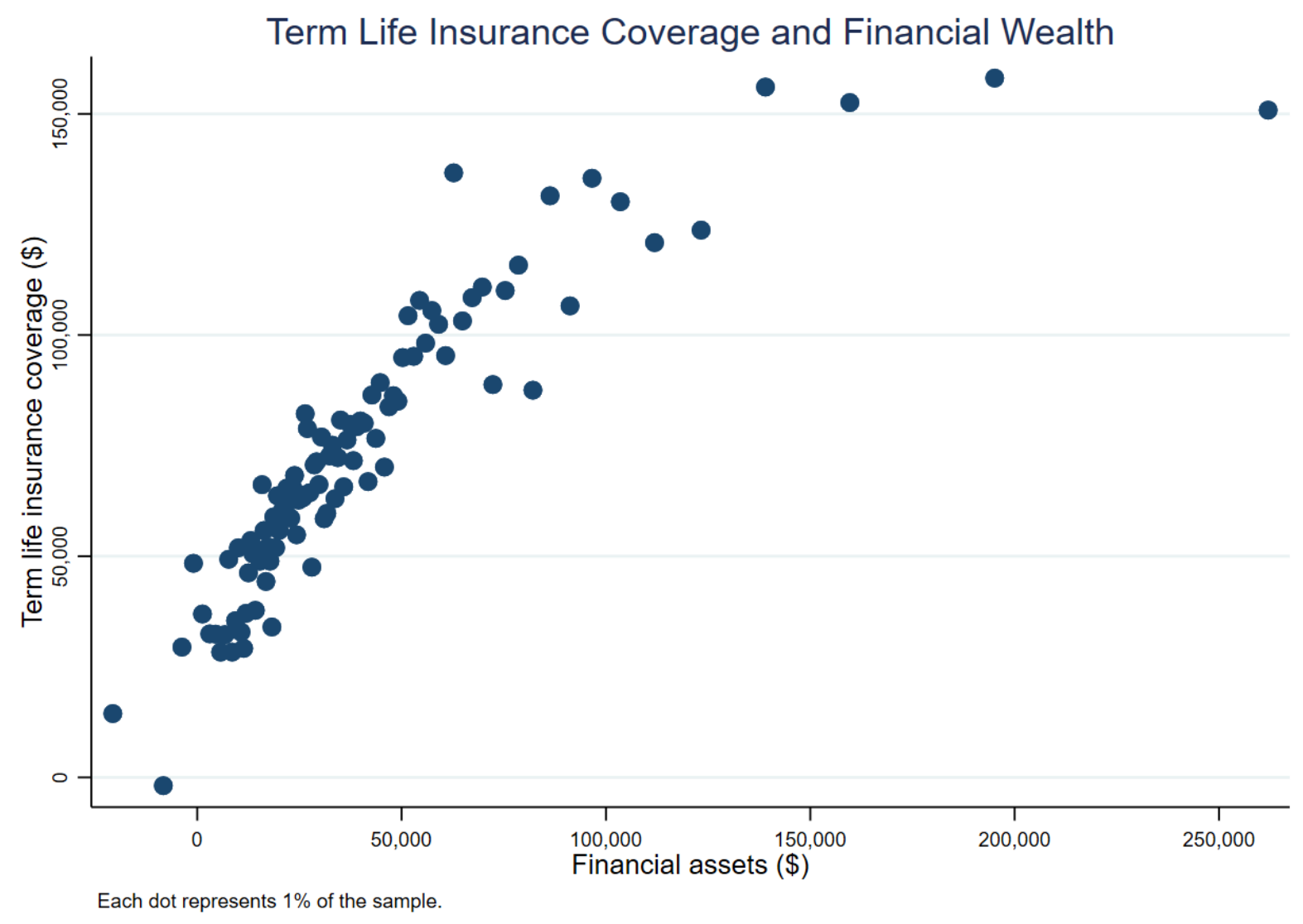

Figure 2: Term life insurance coverage limit as a function of financial wealth. This figure shows the average life insurance coverage limit for various levels of financial wealth (i.e., 100 wealth bins), controlling for all other variables in Table 4: dependents' expected spending, own death probability, housing wealth, and state fixed effects. Note that financial assets may be negative when individuals have lower financial assets than would be predicted, given values of the included control variables. 


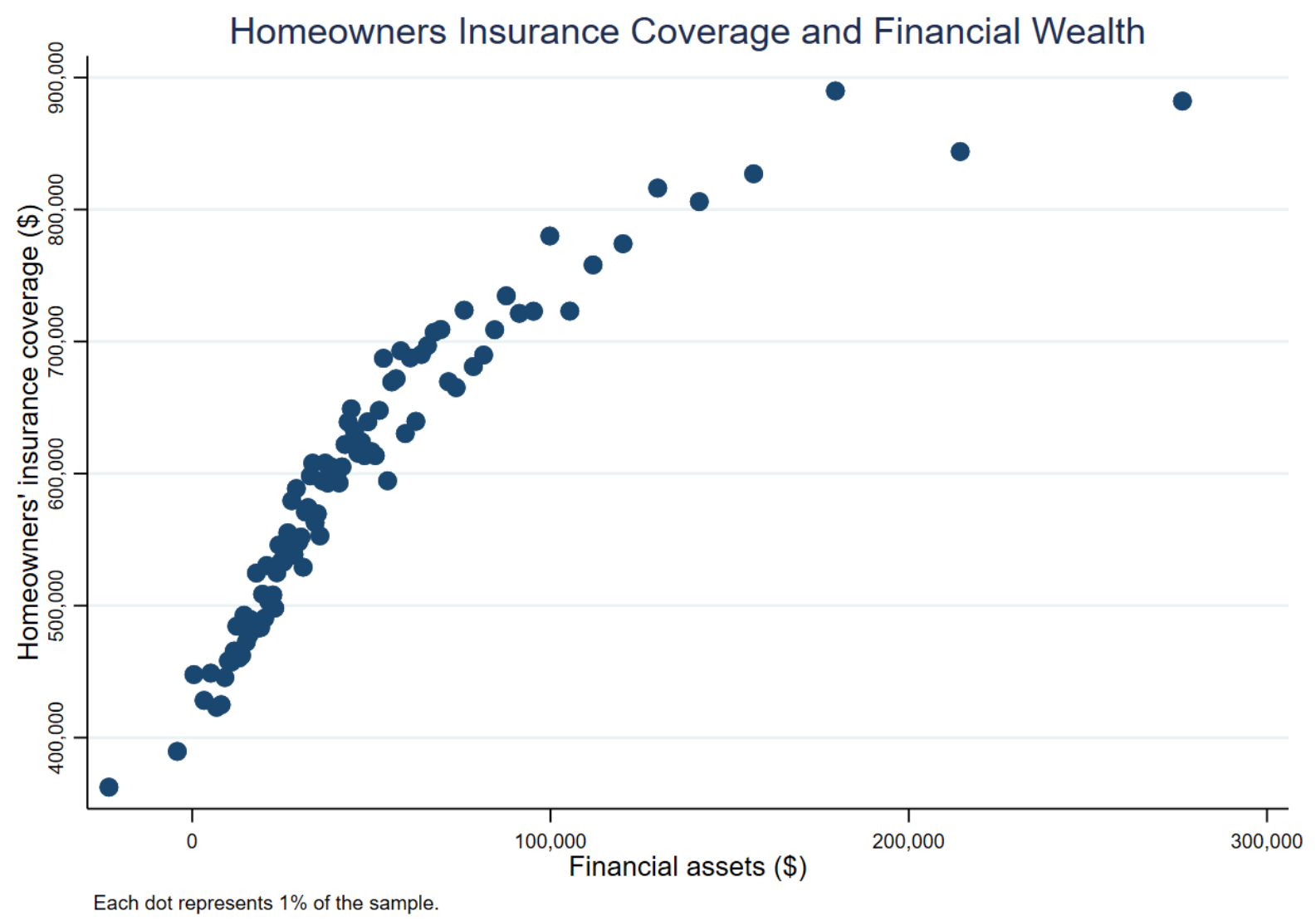

Figure 3: Homeowners insurance coverage limit as a function of financial wealth. This figure shows the average homeowners insurance coverage limit for various levels of financial wealth (i.e., 100 wealth bins), controlling for the value of the home insured, as well as state fixed effects. Note that financial assets may be negative when individuals have lower financial assets than would be predicted, given values of the included control variables. 


\section{Asset Allocation and Financial Wealth}
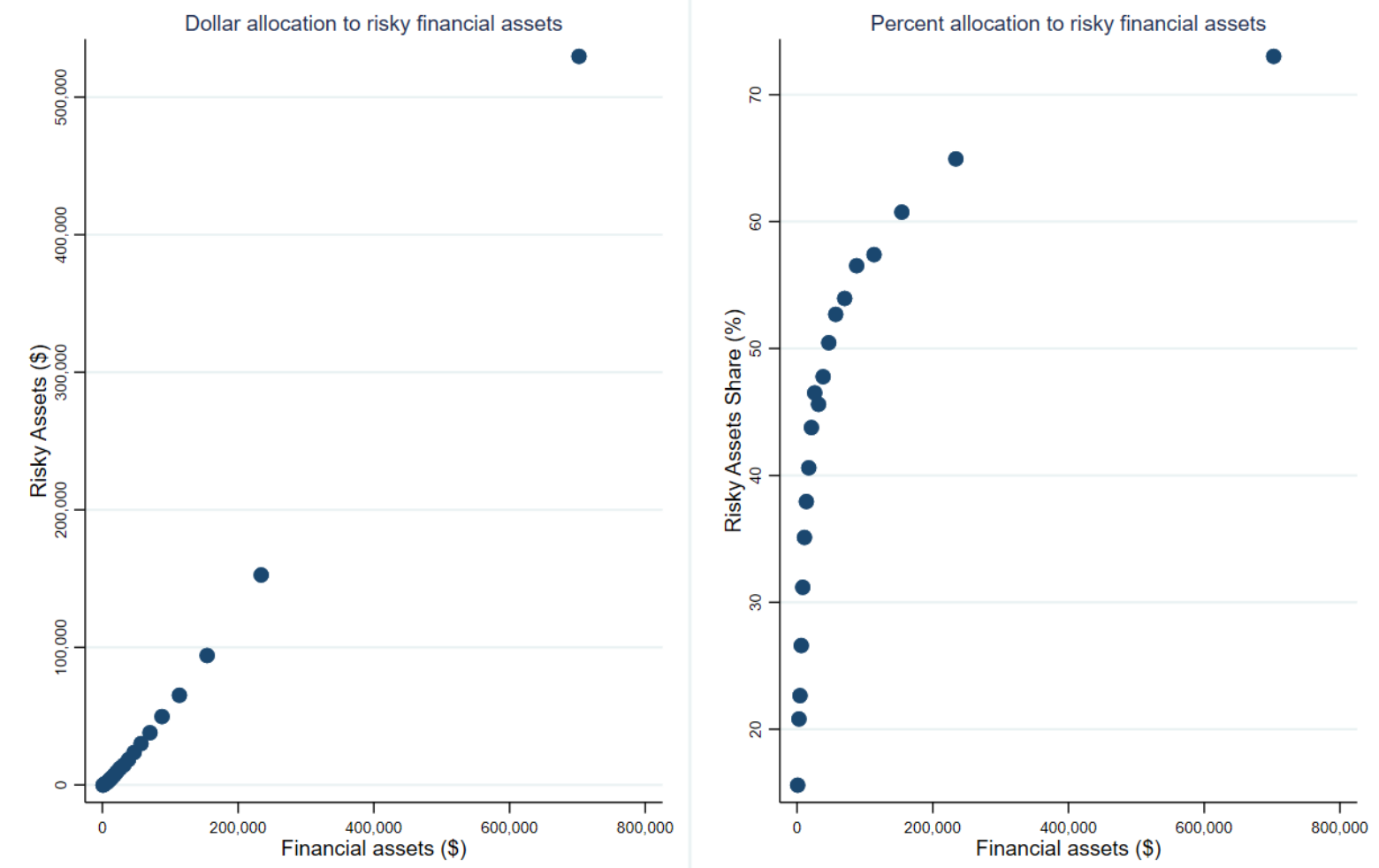

Each dot represents $5 \%$ of the sample.

Figure 4: Risk taking in investment portfolios. This figure shows the allocation to risky assets in individuals' financial portfolios for various levels of financial wealth (i.e. 20 wealth bins). These portfolios are comprised of safe assets (saving and checking accounts, CDs) and risky financial assets in investment accounts (e.g., mutual funds, equities) available through the data provider. 


\section{Life Insurance and Background Risk}
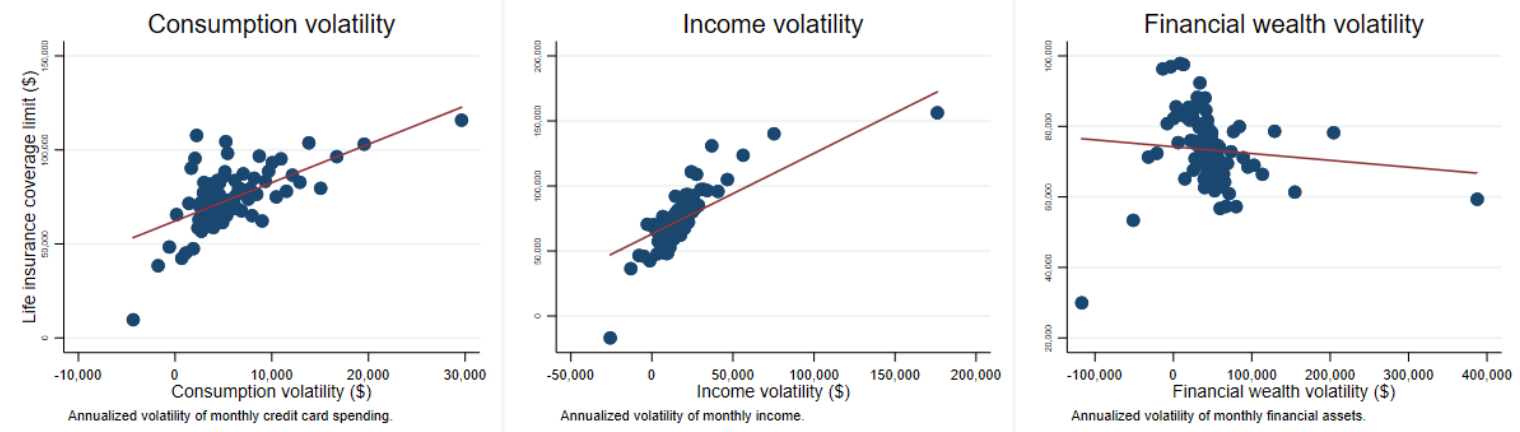

Homeowners Insurance and Background Risk
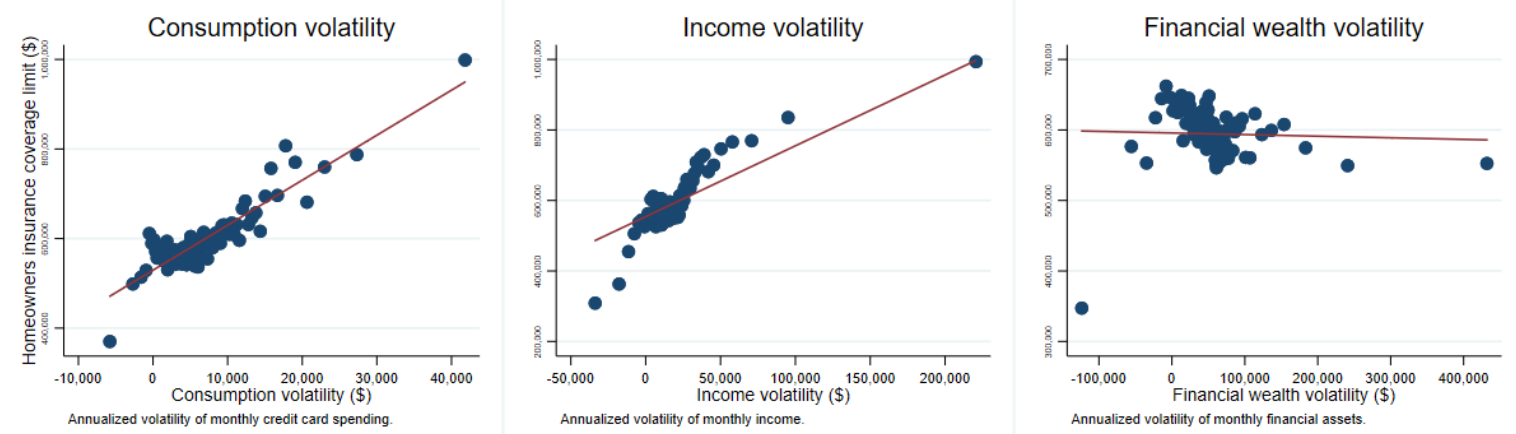

Volatility annualized by multiplying monthly standard deviations by sqrt(12). See subgraphs for specific definitions. Each dot represents $1 \%$ of the sample.

Figure 5: Background risk and insurance coverage limits. This figure shows the average life insurance coverage limits (top row) and homeowners insurance coverage limits (bottom row) across bins in the distribution of consumption volatility, income volatility, and wealth volatility, accounting for the same control variables as in Table 10. Note that volatility values may be negative when individuals have lower volatility than would be predicted, given values of the included control variables. 


\section{Liquidity Constraints and Financial Wealth}
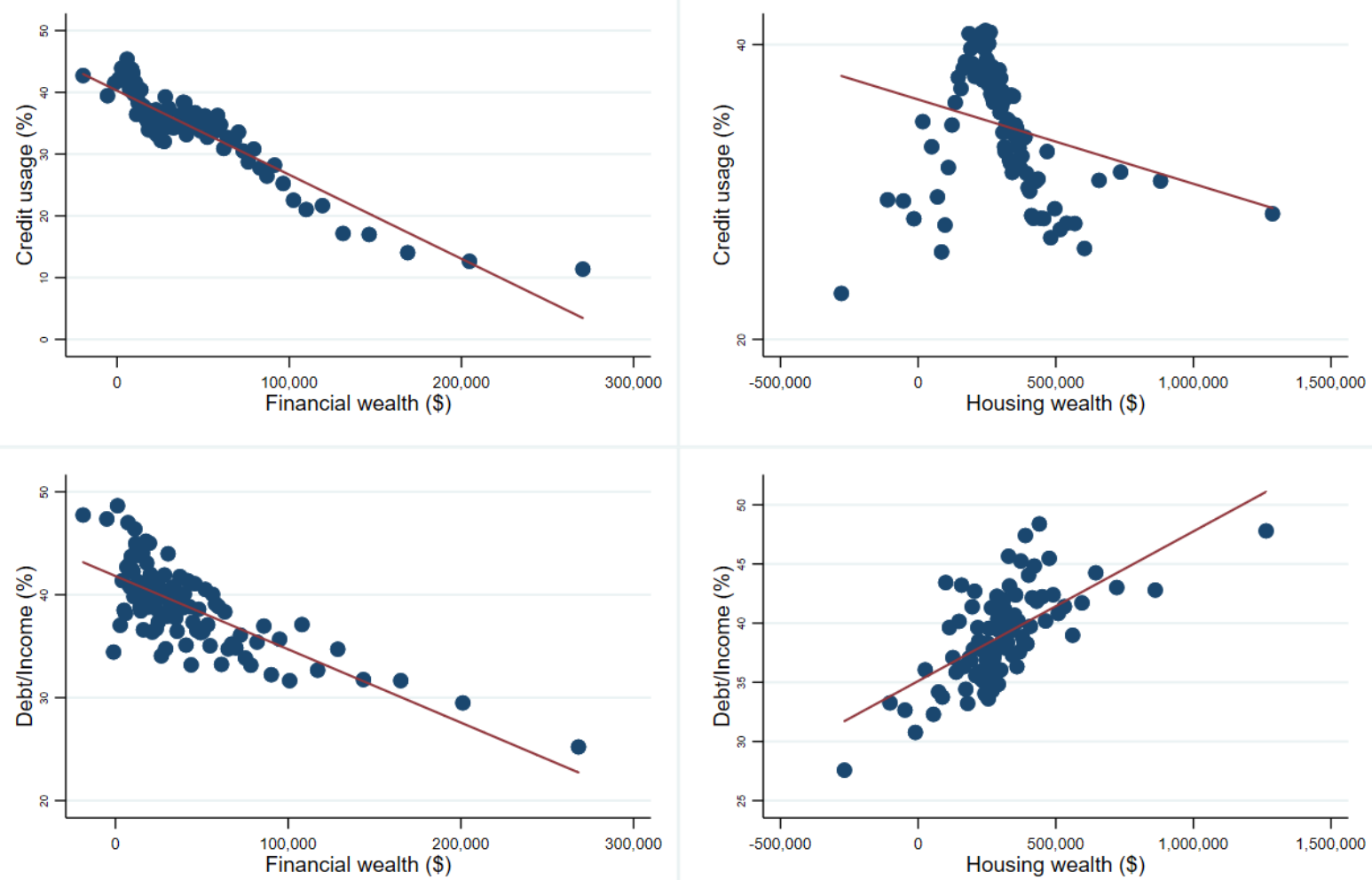

Each dot represents $1 \%$ of the sample.

Figure 6: Liquidity constraints by wealth levels. This figure plots credit use and debtto-income, our two liquidity measures, as a function of financial wealth and housing wealth (i.e., home value), controlling for state fixed effects. Note that financial or housing wealth may be negative when individuals have lower financial or housing wealth than would be predicted, given values of the included control variables. 


\section{Table 1: Summary statistics}

The summary statistics below refer to data measured at the person level. Some of the variables are obtained by aggregating information from the raw data, which is at the person-month level, during September 2015March 2019.

\begin{tabular}{lrrr}
\hline Number of individuals in the sample & & 63,141 \\
Is female & & $33 \%$ \\
Is married & & $76 \%$ \\
Has children & & $70 \%$ \\
Is homeowner & & $94 \%$ \\
Has mortgage payment & & $62 \%$ \\
Has life insurance & & $36 \%$ \\
Has homeowners insurance (conditional on home ownership) & $89 \%$ \\
\hline \multicolumn{4}{c}{ Median } \\
\hline Age & St. deviation \\
\hline Total annual income & 44 yrs & 43 yrs & 12.5 yrs \\
Financial wealth & $\$ 87,393$ & $\$ 73,815$ & $\$ 85,289$ \\
Home value & $\$ 47,923$ & $\$ 28,978$ & $\$ 102,050$ \\
Life insurance coverage & $\$ 301,387$ & $\$ 244,181$ & $\$ 235,829$ \\
Homeowners insurance coverage & $\$ 374,169$ & $\$ 0$ & $\$ 245,965$ \\
Annual insurance expenditures & $\$ 1,209$ & $\$ 259,302$ & $\$ 462,997$ \\
& & $\$ 501$ & $\$ 2,801$ \\
\hline
\end{tabular}


Table 2: Comparison to 2016 Survey of Consumer Finances ("SCF")

The summary statistics below refer to data measured at the person level. Some of the variables are obtained by aggregating information from the raw data, which is at the person-month level, during September 2015March 2019. SCF summary statistics calculated using 2016 summary extract public data release with all five implicates and supplied survey weights. p25, p50, p75, and p90 refer to the 25th, 50th, 75th, and 90th percentiles respectively.

\begin{tabular}{lcc}
\hline & Sample & SCF \\
\hline Is homeowner & $94 \%$ & $64 \%$ \\
Is married & $76 \%$ & $57 \%$ \\
Is female & $33 \%$ & $27 \%$ \\
Has children & $70 \%$ & $41 \%$ \\
\hline
\end{tabular}

\begin{tabular}{lccc}
\hline & Statistic & Sample & SCF \\
\hline Age & p25 & 35 yrs & 37 yrs \\
& p50 & 43 yrs & 52 yrs \\
& p75 & 51 yrs & 65 yrs \\
& p90 & 60 yrs & 76 yrs \\
\hline Total income & p25 & $\$ 41,628$ & $\$ 29,087$ \\
& p50 & $\$ 73,815$ & $\$ 56,019$ \\
& p75 & $\$ 112,843$ & $\$ 104,282$ \\
& p90 & $\$ 160,644$ & $\$ 187,448$ \\
\hline Earned income & p25 & $\$ 18,916$ & $\$ 0$ \\
& p50 & $\$ 53,659$ & $\$ 33,396$ \\
& p75 & $\$ 89,619$ & $\$ 80,797$ \\
& p90 & $\$ 132,081$ & $\$ 140,048$ \\
\hline Financial wealth & p25 & $\$ 13,754$ & $\$ 1,989$ \\
& p50 & $\$ 28,978$ & $\$ 23,431$ \\
& p75 & $\$ 54,608$ & $\$ 164,854$ \\
& p90 & $\$ 95,305$ & $\$ 636,016$ \\
\hline
\end{tabular}


Table 3: Who has life insurance?

The dependent variable in the OLS models in the table below is an indicator equal to 100 if person has had a term life insurance policy during our sample period, and 0 otherwise. Spending and wealth variables are expressed in hundreds of thousands of dollars, so reported coefficient estimates in the table have fewer decimals. Dependents x mortgage and Dependents $\mathrm{x}$ other loans are indicator variables equal to 1 if an individual is either married or has a child and also has a mortgage or other installment loan payment, respectively. Housing wealth values are not available for the small fraction of zip codes in our data for which Zillow does not report the property value index, hence the different sample size in the last column. Standard errors are clustered by state, and $t$-statistics are shown in parentheses. ${ }^{* * *},{ }^{* *}$, and ${ }^{*}$ indicate significance at the $1 \%, 5 \%$, and $10 \%$ level, respectively.

\begin{tabular}{lrrrr}
\hline $\begin{array}{l}\text { Dependent } \\
\text { variable }\end{array}$ & \multicolumn{4}{c}{ Has life insurance? } \\
\hline$N P V$ of future spending of dependents & 0.64 & 0.72 & 0.47 & 0.43 \\
& $(15.52)^{* * *}$ & $(17.01)^{* * *}$ & $(12.08)^{* * *}$ & $(10.01)^{* * *}$ \\
Dependents x mortgage & 14.39 & 14.56 & 13.32 & 13.15 \\
& $(20.14)^{* * *}$ & $(20.94)^{* * *}$ & $(19.83)^{* * *}$ & $(19.27)^{* * *}$ \\
Dependents x other loans & 2.05 & 2.79 & 3.96 & 3.95 \\
& $(5.15)^{* * *}$ & $(7.13)^{* * *}$ & $(10.34)^{* * *}$ & $(10.59)^{* * *}$ \\
Probability of death next year & & 2.41 & 1.97 & 2.01 \\
& & $(6.97)^{* * *}$ & $(6.27)^{* * *}$ & $(6.27)^{* * *}$ \\
Financial wealth & & & 12.54 & 12.14 \\
& & & $(18.94)^{* * *}$ & $(18.91)^{* * *}$ \\
Housing wealth & & & & 0.93 \\
& & & & $(4.12)^{* * *}$ \\
\hline State FEs & Yes & Yes & Yes & Yes \\
\hline$R^{2}$ & 0.038 & 0.042 & 0.054 & 0.055 \\
Observations & 59,722 & 59,722 & 59,722 & 58,559 \\
\hline
\end{tabular}


Table 4: Extent of life insurance coverage

The dependent variable in the OLS models in the table below is the coverage limit for term life insurance policies held by individuals in the sample. It equals zero for those without such policies. The coverage limit, spending, and wealth variables are expressed in hundreds of thousands of dollars. Dependents x mortgage and Dependents x other loans are indicator variables equal to 1 if an individual is either married or has a child and also has a mortgage or other installment loan payment, respectively. Housing wealth values are not available for the small fraction of zip codes in our data for which Zillow does not report the property value index, hence the different sample size in the last column. Standard errors are clustered by state, and $t$-statistics are shown in parentheses. ${ }^{* * *},{ }^{* *}$, and ${ }^{*}$ indicate significance at the $1 \%, 5 \%$, and $10 \%$ level, respectively.

\begin{tabular}{|c|c|c|c|c|c|}
\hline \multirow{2}{*}{$\begin{array}{l}\text { Dependent } \\
\text { variable }\end{array}$} & \multicolumn{5}{|c|}{ Life insurance coverage limit } \\
\hline & \multicolumn{4}{|c|}{-entire sample- } & holders only \\
\hline \multirow[t]{2}{*}{$N P V$ of future spending of dependents } & 0.06 & 0.06 & 0.04 & 0.04 & 0.10 \\
\hline & $(14.54)^{* * *}$ & $(14.28)^{* * *}$ & $(10.92)^{* * *}$ & $(10.23)^{* * *}$ & $(7.82)^{* * *}$ \\
\hline \multirow[t]{2}{*}{ Dependents mortgage } & 0.40 & 0.40 & 0.33 & 0.32 & 0.43 \\
\hline & $(11.21)^{* * *}$ & $(11.12)^{* * *}$ & $(10.78)^{* * *}$ & $(9.33)^{* * *}$ & $(5.45)^{* * *}$ \\
\hline \multirow[t]{2}{*}{ Dependents other loans } & -0.06 & -0.07 & 0.00 & 0.00 & -0.19 \\
\hline & $(-3.26) * *$ & $(-3.59) * * *$ & $(0.00)$ & $(0.19)$ & $(-2.34)^{*}$ \\
\hline \multirow[t]{2}{*}{ Probability of death next year } & & -0.02 & -0.04 & -0.04 & -0.23 \\
\hline & & $(-6.47)^{* * *}$ & $(-11.37)^{* * *}$ & $(-11.21)^{* * *}$ & $(-3.31)^{* *}$ \\
\hline \multirow[t]{2}{*}{ Financial wealth } & & & 0.73 & 0.68 & 1.51 \\
\hline & & & $(16.17)^{* * *}$ & $(15.26)^{* * *}$ & $(13.44)^{* * *}$ \\
\hline \multirow[t]{2}{*}{ Housing wealth } & & & & 0.07 & 0.20 \\
\hline & & & & $(5.86)^{* * *}$ & $(5.06)^{* * *}$ \\
\hline State FEs & Yes & Yes & Yes & Yes & Yes \\
\hline$R^{2}$ & 0.031 & 0.032 & 0.050 & 0.053 & 0.117 \\
\hline Observations & 57,586 & 57,586 & 57,586 & 56,988 & 10,039 \\
\hline
\end{tabular}


Table 5: Who has property insurance?

The dependent variable in the OLS model in the first column is an indicator equal to 100 if person has a property-related insurance policy during our sample period, and 0 otherwise. Property-related policies include homeowners, renters, automobile, fire, boat, and valuable personal property insurance. 98\% of individuals in the sample have at least one of such policies. The dependent variable in the second column is an indicator equal to 100 if the person has homeowners insurance, and the sample is limited to people who own homes. Wealth variables are expressed in hundreds of thousands of dollars, so reported coefficient estimates in the table have fewer decimals. Has mortgage and has other loans are indicator variables equal to 1 if an individual has a mortgage or other installment loan payment, respectively. Standard errors are clustered by state, and $t$-statistics are shown in parentheses. ${ }^{* * *},{ }^{* *}$, and ${ }^{*}$ indicate significance at the $1 \%$, $5 \%$, and $10 \%$ level, respectively.

\begin{tabular}{lrr}
\hline $\begin{array}{l}\text { Dependent } \\
\text { variable }\end{array}$ & $\begin{array}{c}\text { Has any property } \\
\text { insurance? } \\
\text {-ntire sample-- }\end{array}$ & $\begin{array}{c}\text { Has homeowners } \\
\text { insurance? }\end{array}$ \\
-homeowners only-
\end{tabular}




\section{Table 6: Extent of homeowners insurance coverage}

The dependent variable in the OLS model in the first column is equal to the value of the coverage limit on the homeowners insurance policies of the individuals in the sample who purchase such policies from the financial institution providing the data. The dependent variable in the second column is the ratio of the coverage limit to the value of the house, i.e., the fraction of the asset insured. The coverage limit and wealth variables are expressed in hundreds of thousands of dollars. Housing wealth and home value refer to the same quantity, namely, the Zillow property value for the zip code of residence of individuals in the sample. Standard errors are clustered by state, and $t$-statistics are shown in parentheses. ${ }^{* * *},{ }^{* *}$, and ${ }^{*}$ indicate significance at the $1 \%, 5 \%$, and $10 \%$ level, respectively.

\begin{tabular}{lrr}
\hline $\begin{array}{l}\text { Dependent } \\
\text { variable }\end{array}$ & $\begin{array}{r}\text { Homeowners } \\
\text { insurance } \\
\text { coverage limit }\end{array}$ & $\begin{array}{r}\text { Homeowners insurance } \\
\text { coverage limit/ } \\
\text { home value }\end{array}$ \\
\hline Financial wealth & 2.25 & \\
& $(23.69)^{* * *}$ \\
Housing wealth & 0.37 & \\
& $(4.93)^{* * *}$ & 3.25 \\
Financial wealth/ & & $(17.90)^{* * *}$ \\
housing wealth & Yes & Yes \\
\hline State FEs & 0.124 & 0.217 \\
\hline$R^{2}$ & 36,929 & 36,929 \\
\hline
\end{tabular}


Table 7: Life insurance prices

The dependent variable in the OLS models in the table is the price paid for life insurance by the individuals in the sample who have policies with the financial institution providing the data and for whom we observe premiums. The price is expressed as cents paid annually per dollar of coverage. Coverage, wealth, or income variables are expressed in hundreds of thousands of dollars. Standard errors are clustered by state, and $t$-statistics are shown in parentheses. ${ }^{* *},{ }^{* *}$, and ${ }^{*}$ indicate significance at the $1 \%, 5 \%$, and $10 \%$ level, respectively.

\begin{tabular}{lrr}
\hline $\begin{array}{l}\text { Dependent } \\
\text { variable }\end{array}$ & \multicolumn{2}{c}{$\begin{array}{c}\text { Annual price of life insurance, } \\
\text { in cents per dollar of coverage }\end{array}$} \\
\hline Life insurance coverage limit & -0.02 & -0.02 \\
& $(-12.82)^{* * *}$ & $(-13.89)^{* * *}$ \\
Probability of death next year & 0.41 & 0.42 \\
& $(12.64)^{* * *}$ & $(13.15)^{* * *}$ \\
Financial wealth & 0.04 & \\
& $(4.67)^{* * *}$ & \\
Housing wealth & -0.00 & \\
& $(-1.74)$ & 0.03 \\
Annual income & & $(4.58)^{* * *}$ \\
\hline State FEs & & Yes \\
\hline$R^{2}$ & 0.198 & 0.204 \\
Observations & 8,335 & 8,427 \\
\hline
\end{tabular}


Table 8: Homeowners insurance prices

The dependent variable in the OLS models in the table is the price paid for property insurance by the individuals in the sample who have homeowners insurance policies with the financial institution providing the data and for whom we observe premiums. The price is expressed as cents paid annually per dollar of coverage. Coverage, wealth, or income variables are expressed in hundreds of thousands of dollars. Standard errors are clustered by state, and $t$-statistics are shown in parentheses. ${ }^{* * *},{ }^{* *}$, and ${ }^{*}$ indicate significance at the $1 \%, 5 \%$, and $10 \%$ level, respectively.

\begin{tabular}{lrr}
\hline $\begin{array}{l}\text { Dependent } \\
\text { variable }\end{array}$ & $\begin{array}{r}\text { Annual price of homeowners insurance, } \\
\text { in cents per dollar of coverage }\end{array}$ \\
\hline Homeowners coverage limit & -0.03 & \\
Overall property coverage limit & $(-29.46)^{* * *}$ & -0.01 \\
Financial wealth & & $(-24.95)^{* * *}$ \\
& 0.09 & 0.04 \\
Housing wealth & $(10.19)^{* * *}$ & $(8.37)^{* * *}$ \\
& 0.03 & 0.00 \\
\hline State FEs & $(10.72)^{* * *}$ & $(3.81)^{* * *}$ \\
\hline$R^{2}$ & Yes & Yes \\
Observations & 0.073 & 0.046 \\
\hline
\end{tabular}


Table 9: Volatility of consumption, income, and wealth as a function of wealth levels The dependent variables in the OLS models in the table are the annualized volatility of consumption based on the person's monthly credit card spending during the sample period, the annualized volatility of their income, also constructed based on the monthly income time series for each individual, and the annualized volatility of the value of financial wealth and housing-related wealth (the latter is only calculated for homeowners, hence the smaller sample in the last column). All of the variables are expressed in dollars. Standard errors are clustered by state, and $t$-statistics are shown in parentheses. ${ }^{* *},{ }^{* *}$, and ${ }^{*}$ indicate significance at the $1 \%, 5 \%$, and $10 \%$ level, respectively.

\begin{tabular}{lrrrr}
\hline $\begin{array}{l}\text { Dependent } \\
\text { variable }\end{array}$ & $\begin{array}{r}\text { Consumption } \\
\text { volatility }\end{array}$ & $\begin{array}{l}\text { Income } \\
\text { volatility }\end{array}$ & $\begin{array}{r}\text { Financial wealth } \\
\text { volatility }\end{array}$ & $\begin{array}{r}\text { Housing wealth } \\
\text { volatility }\end{array}$ \\
\hline Financial wealth & 0.04 & 0.22 & 1.24 & -0.26 \\
(average during sample) & $(16.17)^{* * *}$ & $(18.05)^{* * *}$ & $(33.72)^{* * *}$ & $(-9.76)^{* * *}$ \\
Housing wealth & 0.01 & 0.02 & 0.02 & 0.34 \\
(average during sample) & $(5.47)^{* * *}$ & $(8.56)^{* * *}$ & $(5.19)^{* * *}$ & $(6.66)^{* * *}$ \\
\hline State FEs & Yes & Yes & Yes & Yes \\
\hline$R^{2}$ & 0.095 & 0.144 & 0.499 & 0.106 \\
Observations & 61,826 & 61,826 & 61,826 & 58,175 \\
\hline
\end{tabular}


Table 10: Insurance coverage limits and background risk

The dependent variable in the OLS models in the first three columns in the table below is the coverage limit for term life insurance policies held by individuals in the sample. It equals zero for those without such policies. The dependent variable in the last three columns is equal to the value of the coverage limit on the homeowners insurance policies of the homeowners in the sample who purchase such policies from the financial institution providing the data. Standard errors are clustered by state, and $t$-statistics are shown in parentheses. ${ }^{* *},{ }^{* *}$, and ${ }^{*}$ indicate significance at the $1 \%, 5 \%$, and $10 \%$ level, respectively.

\begin{tabular}{|c|c|c|c|c|c|c|}
\hline \multirow{2}{*}{$\begin{array}{l}\text { Dependent } \\
\text { variable } \\
\text { Financial wealth }\end{array}$} & \multicolumn{3}{|c|}{$\begin{array}{l}\text { Life insurance } \\
\text { coverage limit }\end{array}$} & \multicolumn{3}{|c|}{$\begin{array}{l}\text { Homeowners insurance } \\
\text { coverage limit }\end{array}$} \\
\hline & 0.66 & 0.57 & 0.71 & 1.96 & 1.82 & 2.28 \\
\hline & $(14.86)^{* * *}$ & $(16.23)^{* * *}$ & $(14.51)^{* * *}$ & $(22.33)^{* * *}$ & $(24.42)^{* * *}$ & $(20.13)^{* * *}$ \\
\hline \multirow[t]{2}{*}{ Housing wealth } & 0.07 & 0.06 & 0.07 & 0.31 & 0.33 & 0.38 \\
\hline & $(5.65)^{* * *}$ & $(5.36)^{* * *}$ & $(5.76)^{* * *}$ & $(4.65)^{* * *}$ & $(4.49)^{* * *}$ & $(4.96)^{* * *}$ \\
\hline \multirow[t]{2}{*}{ Consumption volatility } & 2.04 & & & 10.05 & & \\
\hline & $(5.76)^{* * *}$ & & & $(14.51)^{* * *}$ & & \\
\hline \multirow[t]{2}{*}{ Income volatility } & & 0.62 & & & 2.01 & \\
\hline & & $(4.23)^{* * *}$ & & & $(8.43)^{* * *}$ & \\
\hline \multirow[t]{2}{*}{ Wealth volatility } & & & -0.02 & & & -0.02 \\
\hline & & & $(-0.74)$ & & & $(-0.63)$ \\
\hline State FEs & Yes & Yes & Yes & Yes & Yes & Yes \\
\hline Controls & \multicolumn{3}{|c|}{ as in column 4 of Table 4} & \multicolumn{3}{|c|}{ as in column 1 of Table 6} \\
\hline$R^{2}$ & 0.055 & 0.058 & 0.053 & 0.148 & 0.143 & 0.124 \\
\hline Observations & 56,967 & 56,967 & 56,967 & 36,927 & 36,927 & 36,927 \\
\hline
\end{tabular}


Table 11: Litigation risk and the effect of financial wealth on property insurance

The dependent variable in the OLS model in the first two columns is equal to the value of the coverage limit on the homeowners insurance policies of the individuals in the sample who purchase such policies from the financial institution providing the data. The dependent variable in last two columns is the coverage limit for all types of property insurance, including homeowners insurance. The coverage limit and wealth variables are expressed in hundreds of thousands of dollars. Housing wealth and home value refer to the same quantity, namely, the Zillow property value for the zip code of residence of individuals in the sample. High legal risk is an indicator equal to one for states with above average litigation risk, and zero otherwise. Standard errors are clustered by state, and $t$-statistics are shown in parentheses. ${ }^{* * *},{ }^{* *}$, and ${ }^{*}$ indicate significance at the $1 \%, 5 \%$, and $10 \%$ level, respectively.

\begin{tabular}{lrrrr}
\hline $\begin{array}{l}\text { Dependent } \\
\text { variable }\end{array}$ & $\begin{array}{r}\text { Homeowners insurance } \\
\text { coverage limit }\end{array}$ & $\begin{array}{r}\text { All property insurance } \\
\text { coverage limit }\end{array}$ \\
\hline Financial wealth & 2.30 & 2.15 & 3.69 & 3.51 \\
& $(21.90)^{* * *}$ & $(21.40)^{* * *}$ & $(29.58)^{* * *}$ & $(28.37)^{* * *}$ \\
Housing wealth & 0.33 & 0.33 & 0.49 & 0.49 \\
& $(4.97)^{* * *}$ & $(5.06)^{* * *}$ & $(5.25)^{* * *}$ & $(5.35)^{* * *}$ \\
High litigation risk & 0.45 & 0.21 & 0.55 & 0.23 \\
& $(2.34)^{* *}$ & $(1.27)$ & $(2.20)^{* *}$ & $(0.93)$ \\
Financial wealth & \multicolumn{5}{c}{0.55} & 0.71 \\
x High litigation risk & 0.102 & 0.103 & 0.110 & 0.111 \\
\hline$R^{2}$ & 36,929 & 36,929 & 36,929 & 36,929 \\
\hline
\end{tabular}

Table 12: Liquidity constraints and wealth

The dependent variables in the table are measures of liquidity constraints, the credit use ratio (first column) and the debt-to-income ration (second column). Both are expressed as percentage points. Wealth variables are expressed in hundreds of thousands of dollars. Standard errors are clustered by state, and $t$-statistics are shown in parentheses. ${ }^{* * *},{ }^{* *}$, and ${ }^{*}$ indicate significance at the $1 \%, 5 \%$, and $10 \%$ level, respectively.

\begin{tabular}{lrr}
\hline $\begin{array}{l}\text { Dependent } \\
\text { variable }\end{array}$ & \multicolumn{1}{c}{ Credit } & \multicolumn{1}{c}{ Debt/ } \\
Use Ratio & Income Ratio \\
\hline Financial wealth & -13.61 & -7.12 \\
& $(-30.42)^{* * *}$ & $(-11.14)^{* * *}$ \\
Housing wealth & -0.57 & 1.27 \\
& $(-3.69)^{* * *}$ & $(5.65)^{* * *}$ \\
\hline State FEs & Yes & Yes \\
\hline$R^{2}$ & 0.046 & 0.004 \\
Observations & 61,835 & 59,357 \\
\hline
\end{tabular}




\section{Table 13: Insurance coverage and liquidity constraints}

The dependent variable in the OLS models in the first two columns in the table below is the coverage limit for term life insurance policies held by individuals in the sample. It equals zero for those without such policies. The dependent variable in the last two columns is equal to the value of the coverage limit on the homeowners insurance policies of the homeowners in the sample who purchase such policies from the financial institution providing the data. Standard errors are clustered by state, and $t$-statistics are shown in parentheses. ${ }^{* * *}$, ${ }^{* *}$, and ${ }^{*}$ indicate significance at the $1 \%, 5 \%$, and $10 \%$ level, respectively.

\begin{tabular}{lcrrr}
\hline $\begin{array}{l}\text { Dependent } \\
\text { variable }\end{array}$ & \multicolumn{2}{c}{$\begin{array}{c}\text { Life insurance } \\
\text { coverage limit }\end{array}$} & \multicolumn{2}{c}{$\begin{array}{c}\text { Homeowners insurance } \\
\text { coverage limit }\end{array}$} \\
\hline Financial wealth & 0.67 & 0.69 & 2.22 & 2.29 \\
& $(14.86)^{* * *}$ & $(15.17)^{* * *}$ & $(23.22)^{* * *}$ & $(22.91)^{* * *}$ \\
Housing wealth & 0.07 & 0.07 & 0.37 & 0.36 \\
& $(5.89)^{* * *}$ & $(5.74)^{* * *}$ & $(4.88)^{* * *}$ & $(4.71)^{* * *}$ \\
Credit use ratio & -127.48 & & -400.06 & \\
& $(-5.85)^{* * *}$ & & $(-5.19)^{* * *}$ & 223.50 \\
Debt/income ratio & & 37.10 & & $(3.71)^{* * *}$ \\
\hline State FEs & \multicolumn{5}{c}{$(2.55)^{* *}$} & & Yes \\
Controls & Yes & Yes & Yes & 0.122 \\
\hline$R^{2}$ & 0.054 & 0.053 & 0.125 & 35,574 \\
Observations & 56,978 & 54,704 & 36,924 & \\
\hline
\end{tabular}




\section{Table 14: Education and insurance coverage}

The dependent variable in the OLS models in the first column in the table below is the coverage limit for term life insurance policies held by individuals in the sample. It equals zero for those without such policies. The dependent variable in the second column is equal to the value of the coverage limit on the homeowners insurance policies of the homeowners in the sample who purchase such policies from the financial institution providing the data. Education level is captured by an indicator variable equal to one for those individuals who have a college degree, and zero for those who do not have a college degree or those for whom the financial institution providing the data does not have education information. Standard errors are clustered by state, and $t$-statistics are shown in parentheses. ${ }^{* * *},{ }^{* *}$, and ${ }^{*}$ indicate significance at the $1 \%, 5 \%$, and $10 \%$ level, respectively.

\begin{tabular}{lrr}
\hline $\begin{array}{l}\text { Dependent } \\
\text { variable }\end{array}$ & $\begin{array}{c}\text { Life insurance } \\
\text { coverage limit }\end{array}$ & $\begin{array}{r}\text { Homeowners insurance } \\
\text { coverage limit }\end{array}$ \\
\hline Financial wealth & 0.61 & 2.09 \\
Housing wealth & $(14.37)^{* * *}$ & $(23.45)^{* * *}$ \\
& 0.06 & 0.35 \\
Has college degree & $(5.81)^{* * *}$ & $(4.86)^{* * *}$ \\
& 0.45 & 1.05 \\
$(15.56)^{* * *}$ & $(19.37)^{* * *}$ \\
\hline State FEs & Yes & Yes \\
Controls & as in Table 4, col. 4 & as in Table 6, col. 1 \\
\hline$R^{2}$ & 0.061 & 0.136 \\
Observations & 56,988 & 36,929 \\
\hline
\end{tabular}


Table 15: Insurance coverage and wealth, by employer type

The dependent variable in the OLS models in the first and third columns in the table below is the coverage limit for term life insurance policies held by individuals in the sample. It equals zero for those without such policies. The dependent variable in the second and fourth columns is equal to the value of the coverage limit on the homeowners insurance policies of the homeowners in the sample who purchase such policies from the financial institution providing the data. The observations in the first two columns represent individuals who are employed at least at some point during the sample period by the US federal government. The observations in the last two columns represent individuals who do not work for the federal government while in the sample. Standard errors are clustered by state, and $t$-statistics are shown in parentheses. ${ }^{* * *},{ }^{* *}$, and * indicate significance at the $1 \%, 5 \%$, and $10 \%$ level, respectively.

\begin{tabular}{lrrrr}
\hline & \multicolumn{2}{c}{ Government employees } & \multicolumn{2}{c}{ Non-government employees } \\
\cline { 2 - 5 } $\begin{array}{l}\text { Dependent } \\
\text { variable }\end{array}$ & $\begin{array}{c}\text { Life } \\
\text { insurance } \\
\text { coverage limit }\end{array}$ & $\begin{array}{c}\text { Homeowners } \\
\text { insurance } \\
\text { coverage limit }\end{array}$ & $\begin{array}{c}\text { Life } \\
\text { insurance } \\
\text { coverage limit }\end{array}$ & $\begin{array}{c}\text { Homeowners } \\
\text { insurance } \\
\text { coverage limit }\end{array}$ \\
\hline Financial wealth & 0.45 & 1.69 & 0.76 & 2.43 \\
& $(12.98)^{* * *}$ & $(20.60)^{* * *}$ & $(11.27)^{* * *}$ & $(21.27)^{* * *}$ \\
Housing wealth & 0.08 & 0.35 & 0.06 & 0.34 \\
& $(8.86)^{* * *}$ & $(5.35)^{* * *}$ & $(4.62)^{* * *}$ & $(4.18)^{* * *}$ \\
\hline State FEs & Yes & Yes & Yes & Yes \\
Controls as in & Tbl. 4 col. 4 & Tbl. 6 col. 1 & Tbl. 4 col. 4 & Tbl. 6 col. 1 \\
\hline$R^{2}$ & 0.036 & 0.105 & 0.064 & 0.126 \\
Observations & 19,743 & 12,578 & 37,245 & 24,351 \\
\hline
\end{tabular}




\section{Table 16: Within-person wealth-insurance relationship}

This table uses data at the person-month level. The dependent variable in the OLS model in the first column is an indicator equal to 100 if the person had term life insurance in that month, and zero otherwise. The dependent variables in the second and third columns are the coverage limits for that person in that month in terms of life insurance, and homeowners insurance (if the individual owns a home), respectively. The dependent variable in the last column is the ratio of homeowners insurance coverage limit to the value of the home insured. Wealth variables are expressed in hundreds of thousands of dollars. The regressions include controls as in earlier analyses, including state fixed effects, as well as person fixed effects. Standard errors are clustered by person, and $t$-statistics are shown in parentheses. ${ }^{* * *},{ }^{* *}$, and ${ }^{*}$ indicate significance at the $1 \%, 5 \%$, and $10 \%$ level, respectively.

\begin{tabular}{|c|c|c|c|c|}
\hline & $\begin{array}{c}\text { Has } \\
\text { life } \\
\text { insurance? }\end{array}$ & $\begin{array}{c}\text { Life } \\
\text { insurance } \\
\text { coverage limit }\end{array}$ & $\begin{array}{l}\text { Homeowners } \\
\text { insurance } \\
\text { coverage limit }\end{array}$ & $\begin{array}{c}\text { Homeowners insurance } \\
\text { coverage limit/ } \\
\text { home value }\end{array}$ \\
\hline \multirow[t]{2}{*}{ Financial wealth } & 2.05 & 0.05 & 0.30 & \\
\hline & $(12.39)^{* * *}$ & $(5.80)^{* * *}$ & $(9.76)^{* * *}$ & \\
\hline \multirow[t]{2}{*}{ Housing wealth } & 0.82 & 0.02 & 0.61 & \\
\hline & $(15.25)^{* * *}$ & $(6.51)^{* * *}$ & $(19.18)^{* * *}$ & \\
\hline Financial wealth/ & & & & 0.58 \\
\hline housing wealth & & & & $(15.71)^{* * *}$ \\
\hline Person FEs & Yes & Yes & Yes & Yes \\
\hline State FEs & Yes & Yes & Yes & Yes \\
\hline Controls as in & Tbl 3, col. 4 & Tbl 4, col. 4 & Tbl 6, col. 1 & Tbl 6, col. 2 \\
\hline$R^{2}$ & 0.884 & 0.947 & 0.894 & 0.903 \\
\hline Unique individuals & 61,684 & 57,909 & 36,875 & 36,229 \\
\hline Observations & $2,460,580$ & $2,211,782$ & $1,239,574$ & $1,199,833$ \\
\hline
\end{tabular}

